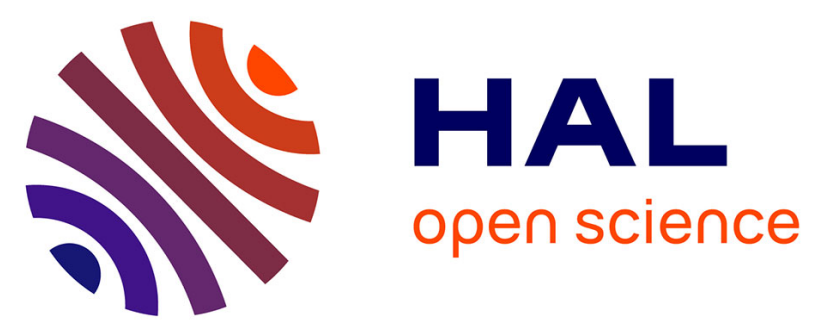

\title{
Dynamical and physical processes leading to tropical cyclone intensification under upper-level trough forcing
}

Marie-Dominique Leroux, Matthieu Plu, David Barbary, Frank Roux, Philippe Arbogast

\section{- To cite this version:}

Marie-Dominique Leroux, Matthieu Plu, David Barbary, Frank Roux, Philippe Arbogast. Dynamical and physical processes leading to tropical cyclone intensification under upper-level trough forcing. Journal of the Atmospheric Sciences, 2013, 70, pp.2547-2565. 10.1175/JAS-D-12-0293.1 . hal01059700v2

\section{HAL Id: hal-01059700 \\ https://hal.science/hal-01059700v2}

Submitted on 14 Jan 2015

HAL is a multi-disciplinary open access archive for the deposit and dissemination of scientific research documents, whether they are published or not. The documents may come from teaching and research institutions in France or abroad, or from public or private research centers.
L'archive ouverte pluridisciplinaire HAL, est destinée au dépôt et à la diffusion de documents scientifiques de niveau recherche, publiés ou non, émanant des établissements d'enseignement et de recherche français ou étrangers, des laboratoires publics ou privés. 


\title{
Dynamical and Physical Processes Leading to Tropical Cyclone Intensification under Upper-Level Trough Forcing
}

\author{
Marie-Dominique Leroux, Matthieu Plu, and David Barbary \\ Laboratoire de l'Atmosphère et des Cyclones, Unité Mixte 8105 CNRS/Météo-France/Université de La \\ Réunion, Sainte Clotilde, Réunion \\ FRANK ROUX \\ Laboratoire d'Aérologie, Unité Mixte 5560 CNRS/Université Paul Sabatier, Toulouse, France
}

PHILIPPE ARBOGAST

CNRM-GAME, Météo-France/CNRS, Toulouse, France

(Manuscript received 18 October 2012, in final form 24 March 2013)

\begin{abstract}
The rapid intensification of Tropical Cyclone (TC) Dora (2007, southwest Indian Ocean) under upper-level trough forcing is investigated. TC-trough interaction is simulated using a limited-area operational numerical weather prediction model. The interaction between the storm and the trough involves a coupled evolution of vertical wind shear and binary vortex interaction in the horizontal and vertical dimensions. The threedimensional potential vorticity structure associated with the trough undergoes strong deformation as it approaches the storm. Potential vorticity (PV) is advected toward the tropical cyclone core over a thick layer from 200 to $500 \mathrm{hPa}$ while the TC upper-level flow turns cyclonic from the continuous import of angular momentum.

It is found that vortex intensification first occurs inside the eyewall and results from PV superposition in the thick aforementioned layer. The main pathway to further storm intensification is associated with secondary eyewall formation triggered by external forcing. Eddy angular momentum convergence and eddy PV fluxes are responsible for spinning up an outer eyewall over the entire troposphere, while spindown is observed within the primary eyewall. The 8 -km-resolution model is able to reproduce the main features of the eyewall replacement cycle observed for TC Dora. The outer eyewall intensifies further through mean vertical advection under dynamically forced upward motion. The processes are illustrated and quantified using various diagnostics.
\end{abstract}

\section{Introduction}

Molinari et al. (1998) closed their study by saying "A great need exists for systematic study of hurricanetrough interactions with a hierarchy of numerical models that isolate the various mechanisms and for observation of the upper troposphere during such interactions" (p. 2643). It is obvious that the "bad trough-good trough" (Hanley et al. 2001) issue is still nowadays one of the biggest challenges facing forecasters in the context of tropical cyclone (TC) rapid intensification prediction. Will an approaching upper-tropospheric

Corresponding author address: Marie-Dominique Leroux, MeteoFrance DIRRE, Cellule Recherche Cyclones, BP4, 97491 Sainte Clotilde Cedex, Réunion.

E-mail: marie-dominique.leroux@meteo.fr synoptic-scale trough produce the intensification or decay of a given TC? This is a critical question that the scientific community needs to address further.

Rapid intensification (RI) is defined for a system beyond the depression stage, when its maximum sustained surface winds increase by $30 \mathrm{kt}\left(15.4 \mathrm{~m} \mathrm{~s}^{-1}\right)$ or more in the course of $24 \mathrm{~h}$ (Kaplan and DeMaria 2003). The main factors influencing TC intensification are known to be ocean heat fluxes (Emanuel 1986; Shay et al. 2000; Lin et al. 2005) and environmental forcing (e.g., Molinari and Vollaro 1989; Hanley et al. 2001; Ritchie and Elsberry 2007; Davidson et al. 2008; Hendricks et al. 2010). Internal processes and asymmetries that modify the vortex structure have also been documented to explain TC intensity changes. They include concentric eyewall cycles (Willoughby et al. 1982), vortex Rossby waves (Montgomery and Kallenbach 1997; Wang 2002), and 
the dynamics of eyewall mesovortices and the mixing of potential vorticity in the TC core (Schubert et al. 1999; Kossin and Schubert 2001; Hendricks et al. 2009), as well as vortical hot towers (Hendricks et al. 2004; Montgomery et al. 2006).

Upper-level troughs (or cutoff lows) that interact with tropical cyclones usually result from the breaking of a planetary Rossby wave train originating from the midlatitudes that propagates equatorward into the subtropical latitudes. Such events are associated with an Ertel potential vorticity (PV) coherent structure at upper levels (Plu et al. 2008), also frequently referred to as a "negative PV anomaly" (Hoskins et al. 1985). As the upper-level geopotential low (trough) and associated jet stream (Thorncroft et al. 1993) approach the tropics, vertical motion and convection may be triggered by stronger upper-level divergence located in the jet entrance and exit regions. A motivation for the present work is that synoptic-scale Rossby waves frequently break in the southwest Indian Ocean (Ndarana and Waugh 2011), providing PV coherent structures that sometimes interact with tropical cyclones.

Some observational studies (DeMaria et al. 1993; Hanley et al. 2001) and numerical modeling of idealized vortices (Montgomery and Farrell 1993) or studies of real storms (Molinari and Vollaro 1989, 1990; Molinari et al. 1995, 1998; Bosart et al. 2000) have documented TC-trough interaction. An interaction is generally said to occur when the relative eddy momentum flux convergence (REFC; Molinari and Vollaro 1989) calculated at $200 \mathrm{hPa}$ over a $300-600-\mathrm{km}$ radial range around the TC center exceeds $10 \mathrm{~m} \mathrm{~s}^{-1}$ day $^{-1}$ for at least two consecutive 12-hourly time periods (DeMaria et al. 1993; Hanley et al. 2001). This parameter acts as a measure of the outflow layer spinup of the TC as a trough comes into the aforementioned annulus. It also characterizes the strength of a given interaction. Hanley et al. (2001) described four categories of interaction and introduced the good trough-bad trough terminology to sort troughs according to TC intensification. They found that external forcing from troughs is a favorable factor for a minority of RI cases since, statistically, RI is more likely to occur when there is no interaction between a TC and an upper-level trough. However, they confirmed that favorable interactions with troughs can occur when a storm is far from its maximum potential intensity (DeMaria et al. 1993; Bosart et al. 2000).

An approaching trough may have opposing effects on the environmental factors that are crucial for TC intensification. On the one hand, it can induce significant vertical wind shear, which is usually detrimental to TC intensity (Kaplan and DeMaria 2003). Vertical shear is known to induce wavenumber-1 asymmetries with convection concentrated in the downshear quadrant, on the left side of the shear vector for TCs in the Northern Hemisphere (Frank and Ritchie 2001). On the other hand, an approaching trough may increase upper-level divergence and enhance outflow poleward of the storm (Ritchie and Elsberry 2007), as well as advect cyclonic PV toward the TC core (Molinari et al. 1995, 1998; Bosart et al. 2000), which is beneficial below the level of the outflow anticyclone ("PV superposition principle"; Molinari et al. 1998).

So far, the proposed mechanisms for the intensification of a TC interacting with an upper-tropospheric trough are the import of cyclonic eddy angular momentum at upper levels (Molinari and Vollaro 1989, 1990), surface spinup resulting from enhanced convergence and vortex stretching in the low-static stability inner core (Montgomery and Farrell 1993), a constructive interference of two cyclonic PV anomalies (Molinari et al. 1995, 1998), and the excitation of an evaporationwind feedback [wind-induced surface heat exchange (WISHE) mode] by the enhanced surface circulation associated with the upper PV anomaly (Molinari et al. 1995). Under strong vertical wind shear conditions, the possible downshear reformation of a TC caused by the approaching-trough-induced vertical motion has also been described (Molinari et al. 2004). Observational studies of rapid intensification in vertical wind shear exceeding $10 \mathrm{~m} \mathrm{~s}^{-1}$ (Shelton and Molinari 2009; Molinari and Vollaro 2010; Nguyen and Molinari 2012) have related strongly asymmetric structures with intense convection (vortical hot towers) developing downshear in the high-inertial-stability region inside the radius of maximum wind. RI was suggested to result from enhanced diabatic heating in that region of highly efficient kinetic energy production, following the theories of Nolan et al. (2007) and Vigh and Schubert (2009). Dry-air intrusion from the lower stratosphere or the triggering of convection by upward velocities associated with PV anomalies (Hoskins et al. 1985) in the vicinity of the inner core are other interesting processes that might play a role in TCtrough interactions.

Molinari and Vollaro $(1989,1990)$ also hypothesized that an outer wind maximum could develop through midlevel spinup forcing associated with eddy momentum source in the outflow layer, but they did not demonstrate it. This assumption was supported by Nong and Emanuel (2003) using an axisymmetric nonhydrostatic model forced by idealized external eddy angular momentum fluxes. The disturbance triggered an "eyewall replacement cycle" (ERC; Willoughby et al. 1982) and the surface circulation amplified through the WISHE mechanism. An ERC was also observed using a simple axisymmetric model, provided that the lower troposphere was 
sufficiently moist. More recently, improved resolution and full-physics TC simulations have resulted in a renewed interest for understanding secondary eyewall formation (SEF) and ERCs that affect hurricane structure and therefore intensity (Abarca and Corbosiero 2011; Sitkowski et al. 2012; Rozoff et al. 2012). Results indicated that any forcing mechanism that produces sufficiently strong and sustained latent heating outside of the primary eyewall will promote SEF and that an increased radial extension of strong winds makes the vortex spinup associated with latent heating more efficient (Rozoff et al. 2012). The role of vortex Rossby waves (VRWs) in the dynamics of SEF has also been emphasized (Qiu et al. 2010; Abarca and Corbosiero 2011; Corbosiero et al. 2012). Recent simulations of the eyewall replacement cycle of Hurricane Wilma (2005) with the high-resolution Weather Research and Forecasting Model (WRF) indicated that VRW propagation is sensitive to horizontal grid resolution and that a minimum 2-km horizontal grid spacing is required to forecast secondary eyewall formation with a full-physics model (Gadoury and Yau 2012).

No conclusion was reached toward a unified theory or conceptual model for TC-trough interaction, which could provide the forecasters with suitable signatures to follow in the various fields produced by a numerical weather prediction system. Also, the various possible pathways to intensification associated with trough forcing may not have all been solved yet or demonstrated to occur for a real storm. With $2.5^{\circ}$ analyses to study the life cycle of Hurricane Elena (1985), Molinari and Vollaro $(1989,1990)$ could only speculate on the actual process by which external forcing might have excited internal processes within $200 \mathrm{~km}$ of the hurricane core. In addition, the modeling results of Nong and Emanuel (2003) are based on an idealized framework. This underscores the need for a three-dimensional mesoscale numerical modeling of a real TC-trough interaction case to confirm and extend the hypothesis of Molinari and Vollaro (1989) and the results of Nong and Emanuel (2003). The present paper is the first attempt of that kind and also the first article to document and to analyze a case of TC rapid intensification under upper-level trough forcing in the southwest Indian Ocean. An operational 8-km-resolution hydrostatic full-physics model will allow diagnoses of trough impacts in the TC core. However, investigations of internal core rearrangements due to vortex Rossby waves cannot be resolved with this model. The European Centre for Medium-Range Weather Forecasts (ECMWF) 25-kmresolution analyses will also provide improved resolution compared to previous large-scale studies.

In section 2, TC Dora (2007) is presented along with the numerical tools used for this study. Sections 3 and 4

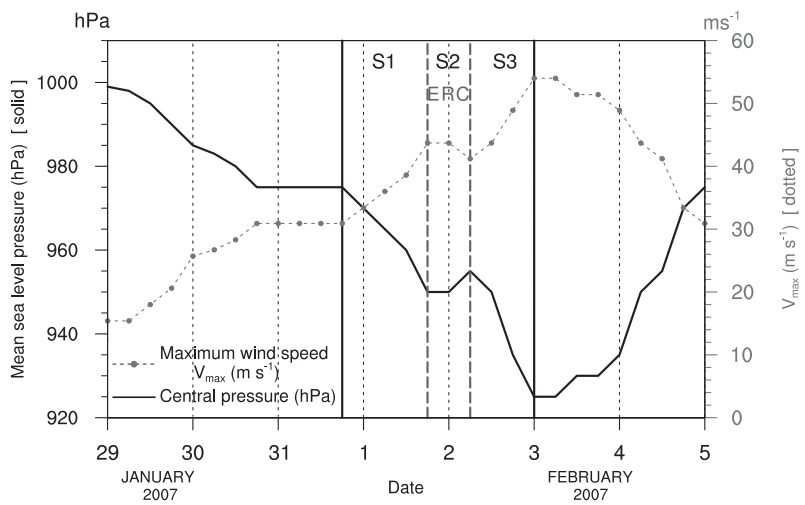

FIG. 1. Best-track intensity estimates for TC Dora from 0000 UTC 29 Jan to 0000 UTC 5 Feb 2007 at 6-h intervals (data from La Reunion Regional Specialized Meteorological Centre). Vertical solid lines mark a 54-h pressure fall that includes two periods of rapid intensification (stages S1 and S3) and an eyewall replacement cycle period (ERC or S2) delimited by vertical dashed lines.

both quantify the TC-trough interaction: section 3 uses a PV approach and analyzes the synoptic dynamical interaction of the two cyclonic circulations (associated with the TC and the approaching trough), while section 4 uses eddy-mean flow diagnostics to further understand the pathway to TC intensification under such upper-level forcing. A summary and discussion follow in section 5 .

\section{Data and tools}

\section{a. Tropical Cyclone Dora}

TC Dora developed from a low pressure system that was spawned on the equatorial side of the monsoon trough in the southwest Indian Ocean on 26 January 2007. The storm rapidly intensified 2 days after it was named. The pressure fell from $975 \mathrm{hPa}$ at 1800 UTC 31 January to a minimum of $925 \mathrm{hPa}$ at 0000 UTC 3 February 2007 (Fig. 1, solid curve). During this 54-h interval, the storm motion recurved from southeastward to southwestward with an average speed of $2.5 \mathrm{~m} \mathrm{~s}^{-1}$ while the system underwent distinct periods of intensity change (Fig. 1, dotted curve): during S1, from 1800 UTC 31 January to 1800 UTC 1 February, 10-min maximum winds increased from $30.9 \mathrm{~m} \mathrm{~s}^{-1}$ (60 kt, severe tropical storm stage) to $43.7 \mathrm{~m} \mathrm{~s}^{-1}$ ( $85 \mathrm{kt}$ ); during S2, from 1800 UTC 1 February to 0600 UTC 2 February, the intensification was temporarily slowed by an ERC (Fig. 1) clearly identified on passive microwave imagery [not shown; available from the Naval Research Laboratory (http://www.nrlmry. navy.mil/tc_pages/tc_home.html)]; and during S3, from 0600 UTC 2 February to 0000 UTC 3 February, winds peaked from $41.2 \mathrm{~m} \mathrm{~s}^{-1}$ ( $80 \mathrm{kt}$ ) to $54 \mathrm{~m} \mathrm{~s}^{-1}$ (105kt, intense tropical cyclone stage). The $30 \mathrm{kt}(24 \mathrm{~h})^{-1}$ threshold 

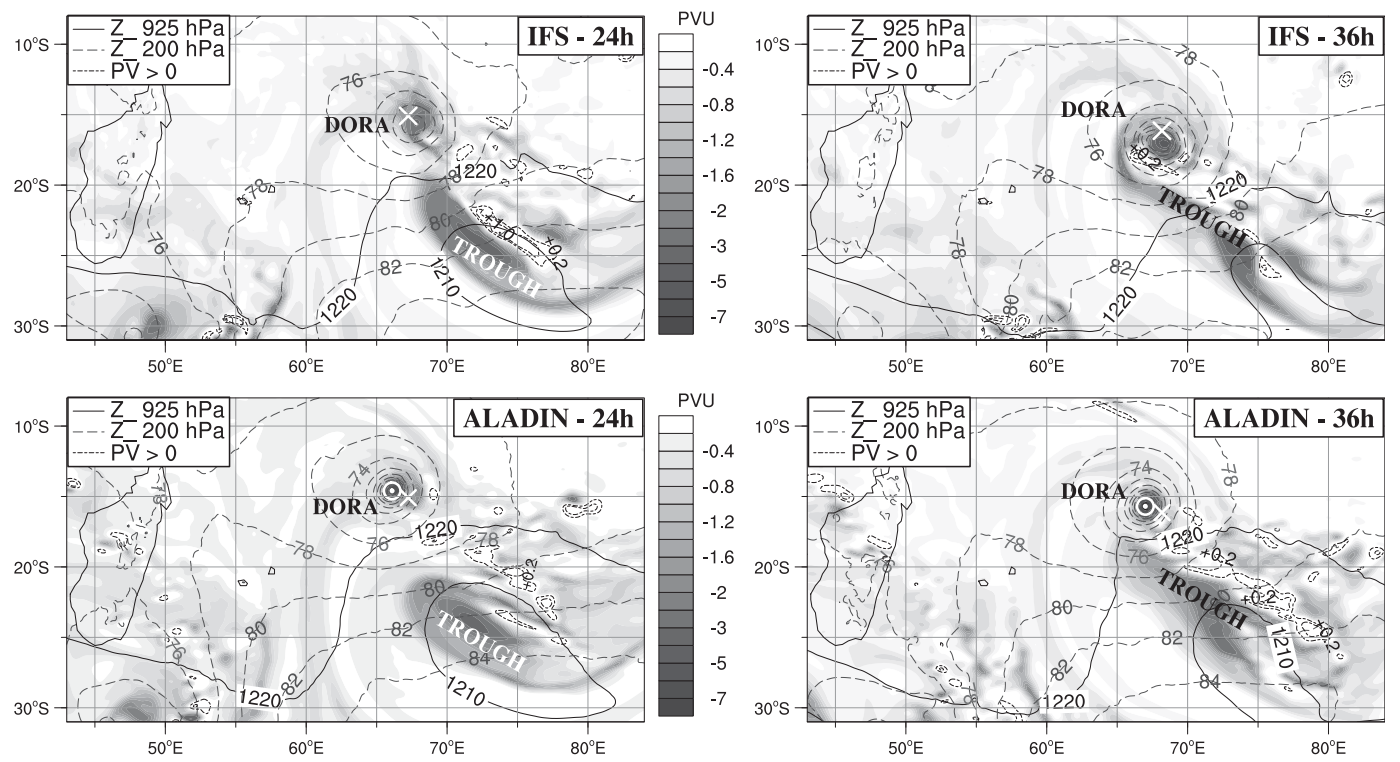

FIG. 2. (top) IFS operational analyses vs (bottom) Aladin-Reunion forecast for TC Dora after (left) 24 and (right) $36 \mathrm{~h}$ from 0600 UTC 31 Jan 2007. Plotted are the Ertel PV field on the 330-K isentropic surface (negative, shaded; positive, 0.2 and 1 PVU dotted contours; $1 \mathrm{PVU} \equiv 10^{-6} \mathrm{~m}^{2} \mathrm{~K} \mathrm{~s}^{-1} \mathrm{~kg}^{-1}$ ) and geopotential height $Z$ (gpm) at 925- and 200-hPa levels. Crosses and encircled dots indicate Dora's best-track and predicted centers, respectively.

characterizing rapid intensifications in the Atlantic and eastern North Pacific basins (Kaplan and DeMaria 2003; Kaplan et al. 2010) was met (or nearly met) during the two periods S1 and S3.

During the first intensification stage (S1), an upperlevel PV coherent structure originating from a Rossby wave breaking event was starting to interact closely with TC Dora (Fig. 2, top panels). ECMWF operational analyses at $25-\mathrm{km}$ resolution indicate that the cyclonic PV anomaly (negative values in the Southern Hemisphere) was initially located on the southern side of Dora, down to the $330-\mathrm{K}$ isentropic level (about $500 \mathrm{hPa}$ ). The PV anomaly was subsequently pulled toward and merged with the high cyclonic PV values associated with the TC circulation at midlevels. The ambient southwesterly vertical wind shear rapidly increased on 31 January as the trough got closer, reaching 20-30 kt $\left(10-15 \mathrm{~m} \mathrm{~s}^{-1}\right)$ early on 1 February [not shown; provided by the Cooperative Institute for Meteorological Satellite Studies (CIMSS, University of Wisconsin) at http://tropic.ssec. wisc.edu/tropic.php]. As a result, a cirrus bow formed in the southwestern side of the storm exposed to the environmental upper flow (satellite images; not shown).

Oceanic conditions were hardly conducive for intensification. After 1200 UTC 29 January, ocean heat content estimates along the storm track [provided by the Regional and Mesoscale Meteorology Branch of the National Oceanic and Atmospheric Administration (NOAA)/ National Environmental Satellite, Data, and Information Service (NESDIS) at http://rammb.cira.colostate. edu/products/tc_realtime/storm.asp?storm_identifier = SH102007] were below the $50 \mathrm{~kJ} \mathrm{~cm}^{-2}$ threshold that has been shown to promote high rates of intensity change (Shay et al. 2000) for tropical cyclones in favorable environmental conditions (i.e., vertical wind shear less than $15 \mathrm{kt}\left(7.7 \mathrm{~m} \mathrm{~s}^{-1}\right)$, midlevel relative humidity greater than $50 \%$, and SSTs warmer than $28.5^{\circ} \mathrm{C}$ ). Values even decreased below $35 \mathrm{~kJ} \mathrm{~cm}^{-2}$ after 1200 UTC 1 February. Sea surface temperatures, almost constant along the storm path, were colder than $28.5^{\circ} \mathrm{C}$ during RI and not warm enough to explain the sudden intensification of the storm.

This makes Dora an interesting case to study rapid intensification under "good trough" forcing. It is worth noting that the stratospheric intrusion was associated with a large zone of dry air that gradually encircled the western side of Dora, according to the Meteosat-7 water vapor channel imagery (Fig. 3a). Unlike Hurricane Claudette (2003) (Shelton and Molinari 2009), Dora was able to remain at hurricane strength despite the detrimental influence of dry air. Also, an Aeroclipper, a lowlevel balloonborne instrumented platform (Duvel et al. 2008), measured the radius of maximum wind $(30 \mathrm{~km})$ at 2200 UTC 31 January 2007.

\section{b. Numerical model}

A 60-h forecast starting at 0600 UTC 31 January 2007 ( $12 \mathrm{~h}$ prior to the onset of $\mathrm{RI}$ ) has been carried out using the limited-area model Aladin-Reunion in its 2011 operational version (hydrostatic, 70 vertical levels, 8 -km 
(a)

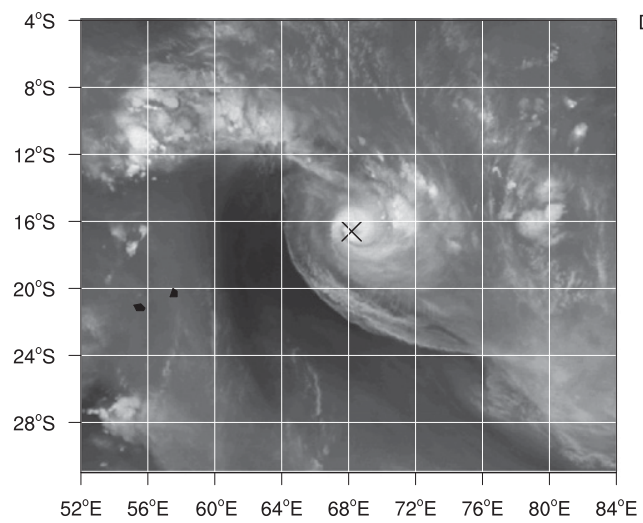

(c)

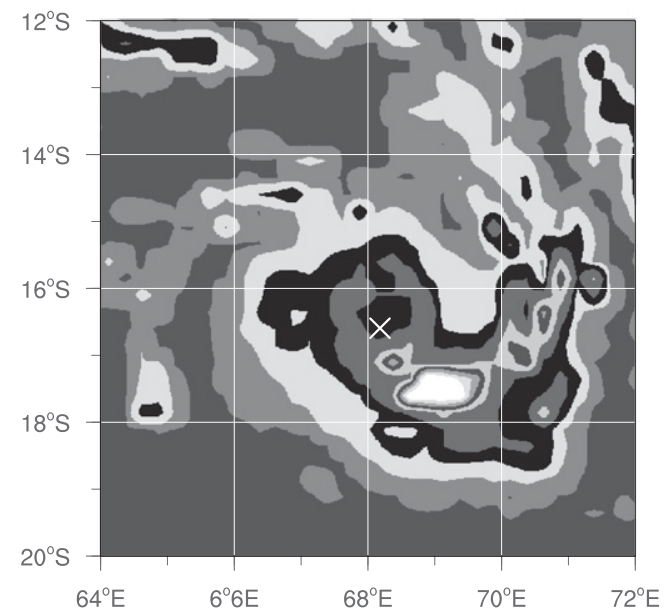

(b)

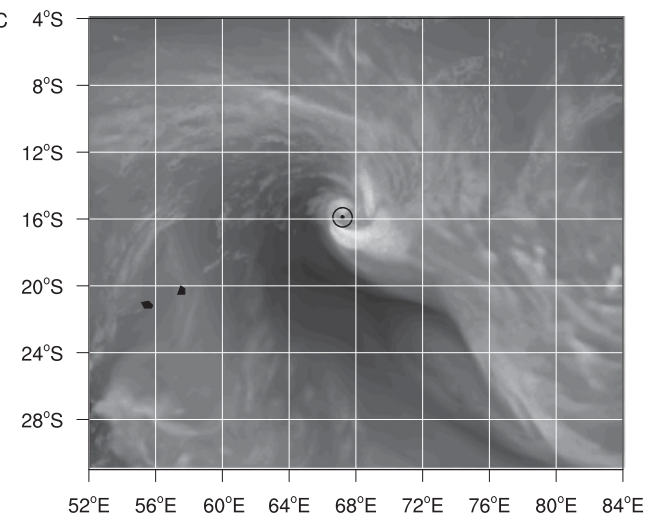

(d)

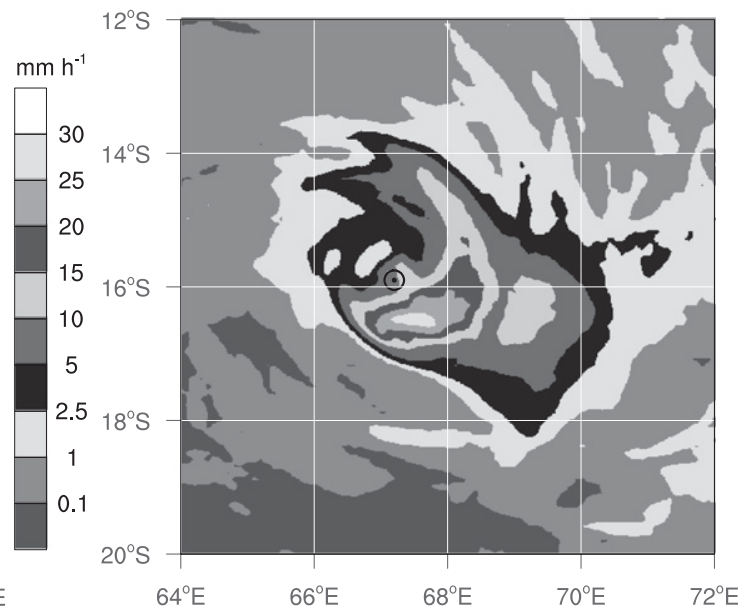

FIG. 3. Water vapor image at 2100 UTC 1 Feb 2007 from (a) Meteosat-7 and (b) Aladin-Reunion 39-h output. Also plotted at the same time is the rain rate $\left(\mathrm{mm} \mathrm{h}^{-1}\right)$ averaged over the past $3 \mathrm{~h}$ calculated from (c) the TRMM-3B42 algorithm and (d) the model output. Crosses and encircled dots indicate Dora's interpolated best-track and predicted centers, respectively.

horizontal resolution; Montroty et al. 2008). The domain extends from $0^{\circ}$ to $32^{\circ} \mathrm{S}$ and from $31.5^{\circ}$ to $88.5^{\circ} \mathrm{E}$, which is much larger than the region displayed in Fig. 2. The initial and lateral boundary conditions are provided by the ECMWF Integrated Forecast System (IFS) global analyses. To obtain a realistic vortex structure and position at the initial time of the forecast, the Aladin's three-dimensional variational data assimilation (3D-Var) of cyclone wind bogus (Montroty et al. 2008 ) is employed. Pseudo observations are extracted at different radii from a three-dimensional vortex constructed following Holland (1980)'s analytical wind profile using intensity and structure estimates from the best-track data. Four radii $(30,50,100$, and $200 \mathrm{~km})$ are used in order to obtain a good representation of the inner storm structure. These pseudo observations are assimilated at 0600 UTC 31 January 2007 in the Aladin 6-h forecast based on an interpolation of the 25-km-resolution ECMWF analysis at 0000 UTC 31 January 2007.

The simulation adequately captures the TC-trough interaction in terms of Ertel's potential vorticity fields when compared to 6-hourly IFS analyses (Fig. 2). Intercomparison of real and synthetic satellite images in the water vapor channel (Figs. 3a,b) confirms that the Aladin model is able to reproduce a key aspect of the interaction - that is, the tongue of dry air that gradually encircles the western side of TC Dora in association with the stratospheric intrusion. The ability of the model to properly resolve convection is assessed through comparisons with the 3-hourly Tropical Rainfall Measuring Mission (TRMM) Multisatellite Precipitation Analysis (TMPA) 3B42 product with horizontal resolution of $0.25^{\circ} \times 0.25^{\circ}$ and maximum precipitation rate of $30 \mathrm{~mm} \mathrm{~h}^{-1}$ (Huffman et al. 2007). Rain rates are similar with maxima localized in the same quadrant of the storm 


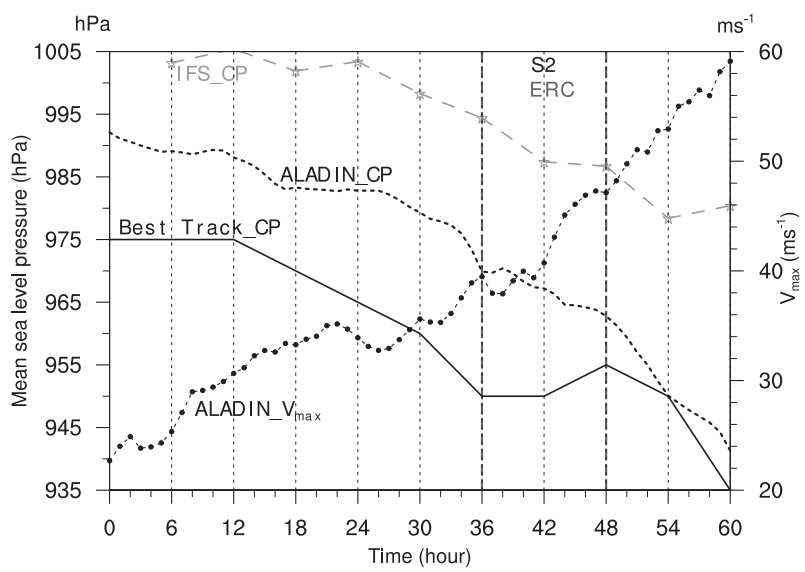

FIG. 4. TC Dora predicted central pressures (CP; hPa, left axis) and $850-\mathrm{hPa}$ maximum mean tangential winds $V_{\max }\left(\mathrm{m} \mathrm{s}^{-1}\right.$, right axis) from base time 0600 UTC 31 Jan. Plotted for reference are pressures from the 2007 IFS forecast initialized at 1200 UTC 31 Jan and from the best track (ERC or S2 as in Fig. 1).

(Figs. 3c,d). Overall, the model correctly captures different aspects of Dora's development and interaction.

Moreover, the evolution of the minimum surface pressure in the model resembles the intensity trend from the best track (Fig. 4), albeit a positive 15-hPa bias from the initial time. The model is skillful in predicting the two periods of rapid intensification with a 12-h interval during which winds do not intensify much. Prediction of the track is successful with errors less than $100 \mathrm{~km}$ during the 60 -h forecast, which is quite competitive by international standards (Franklin 2008). Aladin-Reunion is thus believed to provide reliable information on the response of the vortex to the external forcing.

\section{c. Data processing}

Various diagnostic quantities are considered, either on isobaric or isentropic surfaces, to examine the interaction between the TC and the trough, and elucidate the dynamical and thermodynamical effects that are responsible for Dora's rapid intensification in relation with upper-level forcing. A cylindrical framework centered on the TC is chosen to highlight the asymmetric effects of the trough on the TC symmetric circulation; azimuthal means and deviations from those means are computed. Horizontal bilinear interpolation from a uniform (latitude, longitude) grid to cylindrical coordinates (radius $r$, azimuth $\lambda$ ) is performed with radial resolution of $10 \mathrm{~km}$ and azimuthal resolution of $1^{\circ}$. Azimuth $0^{\circ}$ is north, $90^{\circ}$ is east, $180^{\circ}$ is south, and $270^{\circ}$ is west. Radial and tangential velocity components are $u$ and $v$, respectively. Since TC Dora occurred in the Southern Hemisphere, cyclonic tangential winds, as well as cyclonic relative or potential vorticity, are negative.

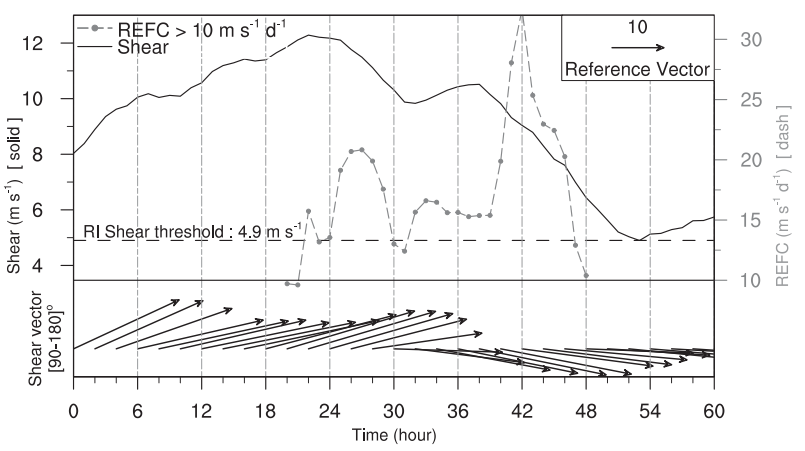

FIG. 5. (top) Evolution of the predicted 850-200-hPa vertical wind shear $\left(\mathrm{ms}^{-1}\right.$, left axis) and relative eddy momentum flux convergence (REFC) modulus for values greater than $10 \mathrm{~m} \mathrm{~s}^{-1}$ day $^{-1}$ (right axis). The climatological shear threshold for RI in the Atlantic basin (Kaplan and DeMaria 2003) is indicated for reference. (bottom) Wind shear vectors averaged over the southeastern quadrant of the storm are drawn at 2-h intervals.

The vortex center is defined as the local extremum in the relative vorticity field at $800 \mathrm{hPa}$ (or $310 \mathrm{~K}$ when isentropic coordinates are used). The use of the massweighted average of the vorticity centers at different levels, local minimum in the mass field, or local maximum in the wind speed give consistent results. The use of $0.1^{\circ}$-resolution outputs prevented any mislocation of the TC center owing to (a) possible mesovortices with relatively high vorticity in the eyewall region or (b) high vorticity associated with cyclonic shear away from the storm center. For diagnostics computed in a stormrelative flow, the vortex motion is subtracted from the absolute wind at all grid points prior to cylindrical conversion.

\section{Synoptic interaction with $P V$ advection}

\section{a. Amplitude and duration of the interaction}

There are different but complementary ways to characterize the interaction of Dora with the approaching trough, both in magnitude and duration. First, the 20-48-h period during which the relative eddy momentum flux convergence (REFC) magnitude at $200 \mathrm{hPa}$ exceeds $10 \mathrm{~m} \mathrm{~s}^{-1}$ day $^{-1}$ (Fig. 5) defines the duration of the interaction. Values greater than $20 \mathrm{~m} \mathrm{~s}^{-1}$ day $^{-1}$ between 38 and $46 \mathrm{~h}$ indicate that the trough is almost entirely contained in the $300-600-\mathrm{km}$ radial range and that convergence of angular momentum by azimuthal eddies induce strong cyclonic spinup in the TC's outflow layer. When the trough penetrates inside $300 \mathrm{~km}$, its contribution to the calculated REFC decreases by definition. Values reach $32.5 \mathrm{~m} \mathrm{~s}^{-1}$ day $^{-1}$, compared to $26.5 \mathrm{~m} \mathrm{~s}^{-1}$ day $^{-1}$ found for Hurricane Elena at the $650-\mathrm{km}$ radius (Molinari and Vollaro 1989). 
(a) $\bar{v}$ at $200 \mathrm{hPa}$

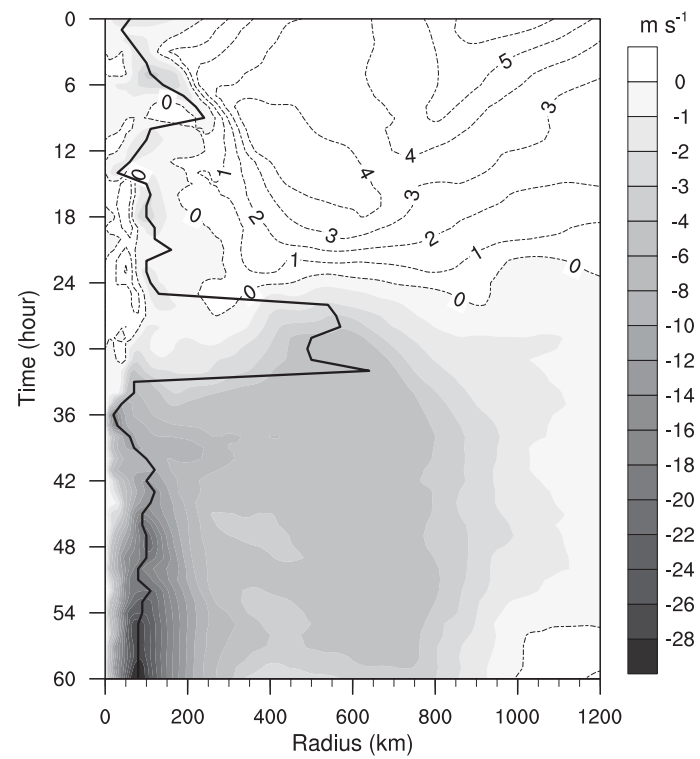

(b) $\bar{u}$ at $200 \mathrm{hPa}$

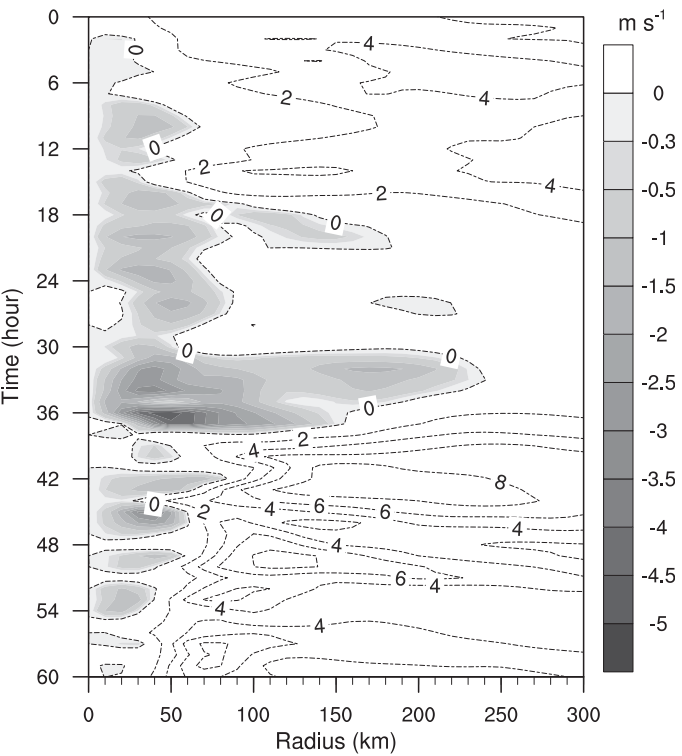

FIG. 6. Radius-time plots of 200-hPa azimuthal-mean (a) tangential wind ( $\mathrm{m} \mathrm{s}^{-1}$; negative, shaded; positive, dotted contours every $1 \mathrm{~m} \mathrm{~s}^{-1}$ ) and (b) radial wind $\left(\mathrm{m} \mathrm{s}^{-1}\right.$; negative, shaded; positive, dotted contours every $\left.2 \mathrm{~m} \mathrm{~s}^{-1}\right)$ during the forecast. The maximum radius is $1200 \mathrm{~km}$ in (a) and $300 \mathrm{~km}$ in (b). The black solid line in (a) indicates the radius of maximum cyclonic (negative) tangential wind at $200 \mathrm{hPa}$.

An interesting aspect of the interaction is related to the azimuthal circulation at upper levels. As the trough enters the domain and moves toward the TC, a cyclonic circulation builds over the whole domain at $200 \mathrm{hPa}$ after $27 \mathrm{~h}$ (Fig. 6a, shaded contours). Between 26 and $33 \mathrm{~h}$, noticeably strong tangential winds are found about $600 \mathrm{~km}$ from the storm center on average (Fig. 6a, black solid line). They materialize the trough and its associated jet streak located in the southeastern quadrant of the storm. The anticyclonic circulation initially present aloft the storm (Fig. 6a, dotted contours) decreases in response to eddy cyclonic spinup exceeding $10 \mathrm{~m} \mathrm{~s}^{-1} \mathrm{day}^{-1}$ (-REFC) after $20 \mathrm{~h}$ (Fig. 5). The TC circulation and associated convection increase and induce an outflow at $200 \mathrm{hPa}$ after about $37 \mathrm{~h}$ of simulation (e.g., Figs. $6 \mathrm{~b}$ and $7 \mathrm{e}$ ). An anticyclonic circulation with a more pronounced outflow can be seen higher, at $100 \mathrm{hPa}$ (not shown).

Second, the vertical wind shear in the $850-200-\mathrm{hPa}$ layer is closely tied to the evolution of the upper trough as it interacts with the storm. The shear is averaged over the $200-800-\mathrm{km}$ annulus range to virtually extract the storm vortex (Kaplan and DeMaria 2003). Figure 5 indicates that Dora is constrained by a strong southwesterly environmental wind shear that peaks at $12 \mathrm{~m} \mathrm{~s}^{-1}$ around $24 \mathrm{~h}$ (solid curve). The weakening of the anticyclonic circulation at upper levels may explain why the environmental shear decreases beyond $24 \mathrm{~h}$. Shear vectors averaged over the southeastern quadrant of the storm show the trough progression with a shift in shear direction (from southwesterly to northwesterly) at about $30 \mathrm{~h}$ (Fig. 5, arrows). The direction, magnitude, and duration of the simulated shear are consistent with the southwesterly deep-layer wind shear of $10-15 \mathrm{~m} \mathrm{~s}^{-1}$ deduced from satellite images early on 1 February (at about $24 \mathrm{~h}$ in the simulation). The shear strength largely exceeds the $4.9 \mathrm{~m} \mathrm{~s}^{-1}$ climatological threshold for RI determined by Kaplan and DeMaria (2003) for tropical cyclones in the Atlantic basin (Fig. 5). Dora therefore joins the other few cases documented in the literature that rapidly intensified even though ambient vertical wind shear was above $10 \mathrm{~m} \mathrm{~s}^{-1}$.

\section{b. Trough-induced asymmetric secondary circulation}

A three-dimensional description of inflow and outflow in the tropical cyclone is provided by Figs. 7-9. From 18 to $40 \mathrm{~h}$, the approaching trough induces a strong southwesterly cross-storm flow at $200 \mathrm{hPa}$ (Fig. 7, arrows). There is an inflow through the southwestern quadrant from $150^{\circ}$ to $270^{\circ}$ (Fig. 8, arrows) and an outflow in the east-southeastern quadrant out to $1200 \mathrm{~km}$ (Fig. 9, arrows). Note that unlike previous studies, the asymmetric radial circulation across the storm affects a deep layer and is found down to $500 \mathrm{hPa}$ (Figs. 8 and 9). The strong northwesterly winds driven by the upper jet stream located in the northern periphery of the trough (Figs. 7a,c) 
(a) $24 \mathrm{~h}-200 \mathrm{hPa}$

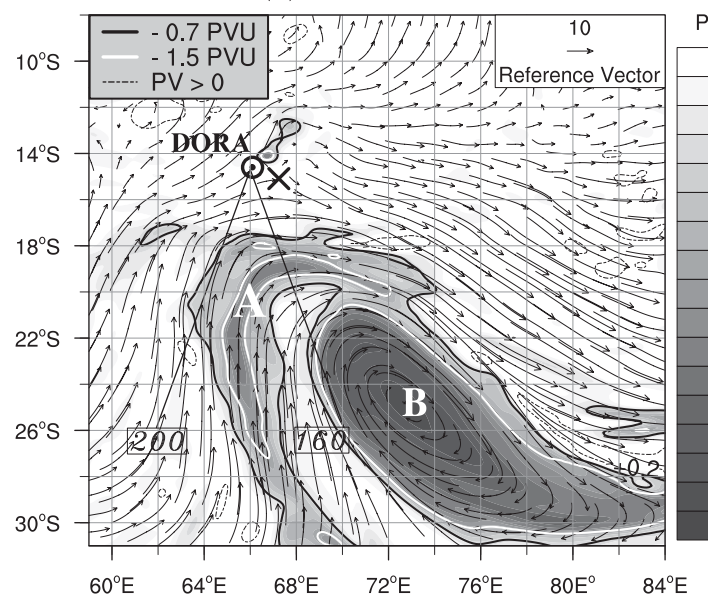

(c) $36 \mathrm{~h}-200 \mathrm{hPa}$

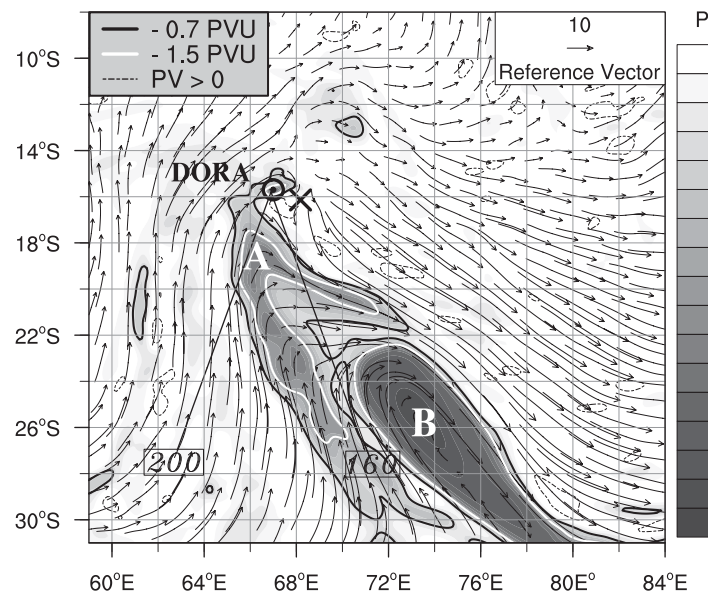

(e) $48 \mathrm{~h}-200 \mathrm{hPa}$

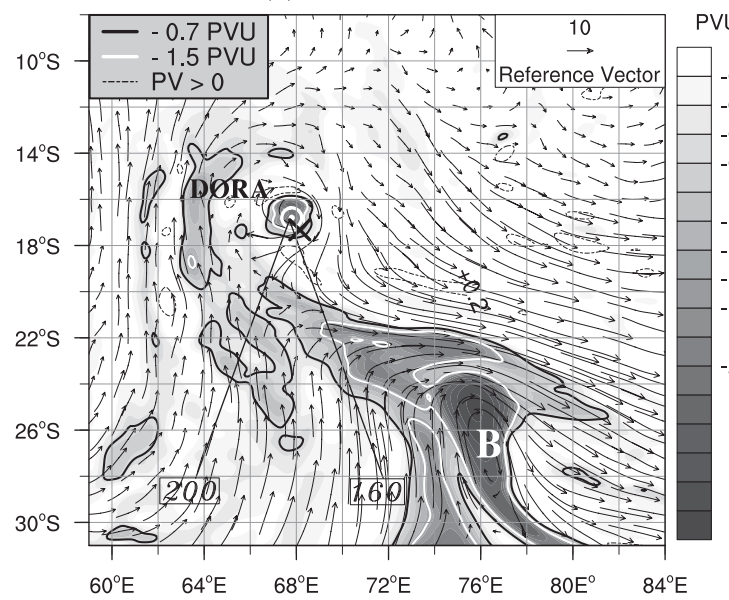

(b) $24 \mathrm{~h}-400 \mathrm{hPa}$

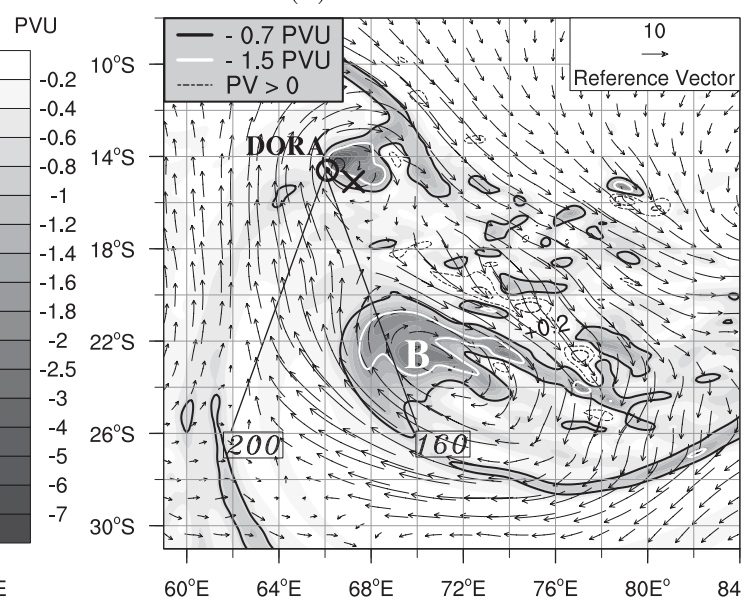

(d) $36 \mathrm{~h}-400 \mathrm{hPa}$

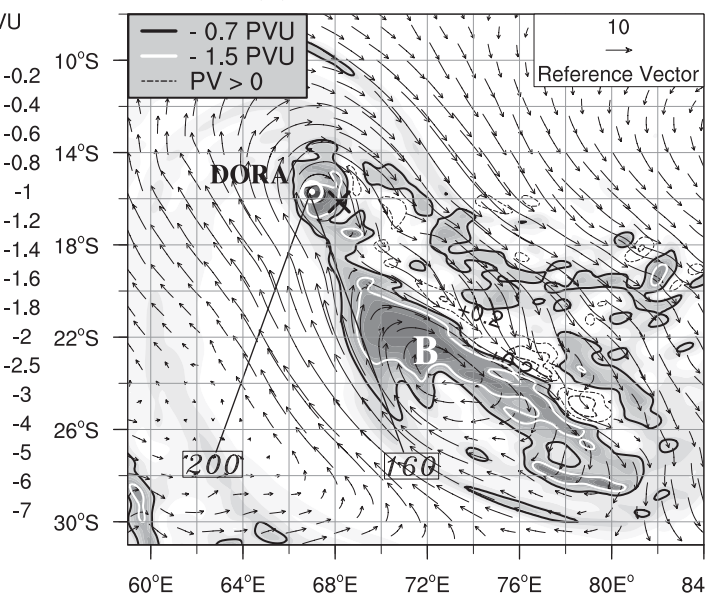

(f) $48 \mathrm{~h}-400 \mathrm{hPa}$

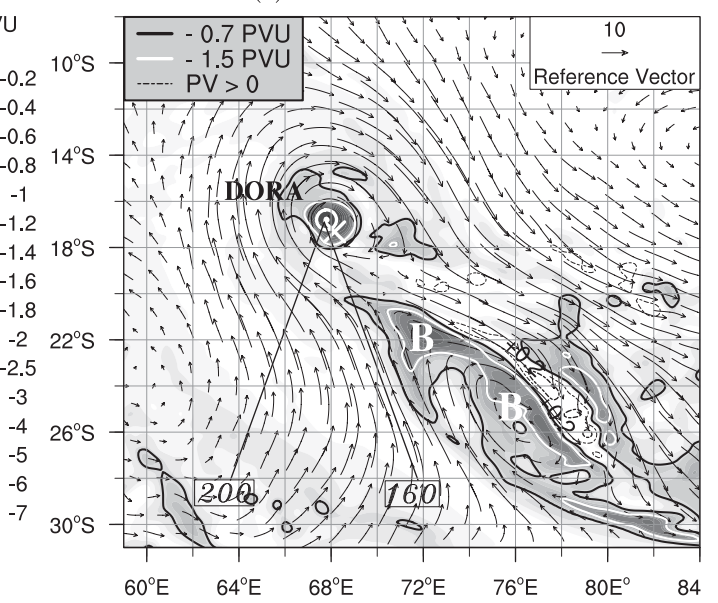

FIG. 7. Wind vectors (arrows) and PV field (negative, shaded with -0.7 and -1.5 PVU contours; positive, 0.2 and 1 PVU dotted contours) at (a),(c),(e) 200 and (b),(d),(f) $400 \mathrm{hPa}$ after (top) 24, (middle) 36, and (bottom) $48 \mathrm{~h}$ of model integration. A cross indicates Dora's best-track center. Black straight lines starting from the TC predicted center (encircled dot) delineate the two 1200-km-long cross sections (azimuths 160 and 200). Labels A and B indicate main $\mathrm{PV}$ advection from the coherent structure toward TC Dora. 
(a) $28 \mathrm{~h}-200^{\circ}$

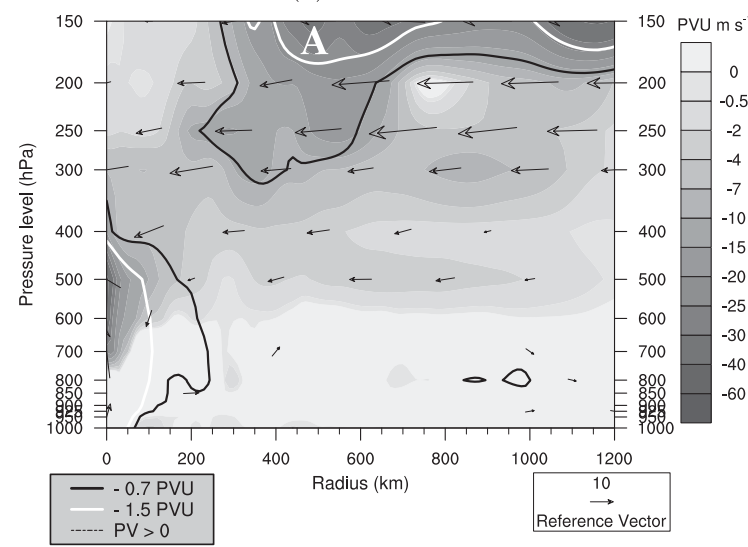

(c) $36 \mathrm{~h}-200^{\circ}$

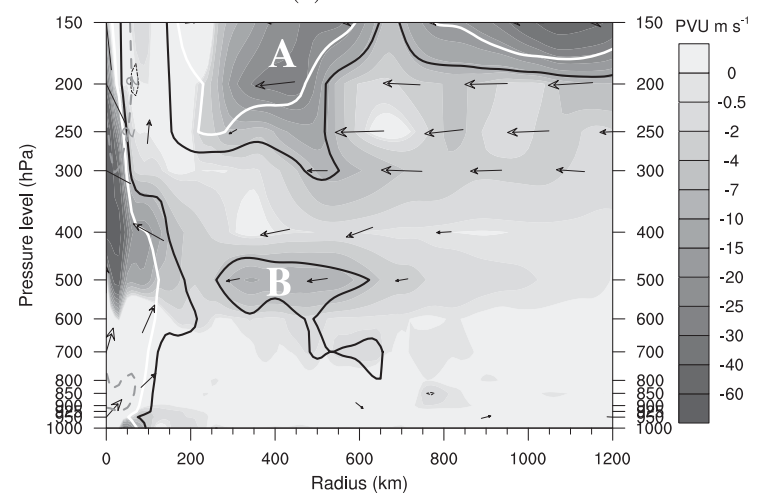

(b) $28 \mathrm{~h}-160^{\circ}$

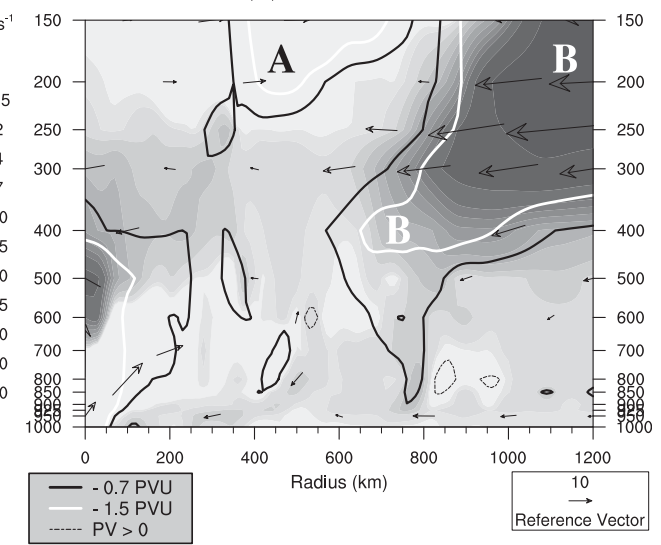

(d) $36 \mathrm{~h}-160^{\circ}$

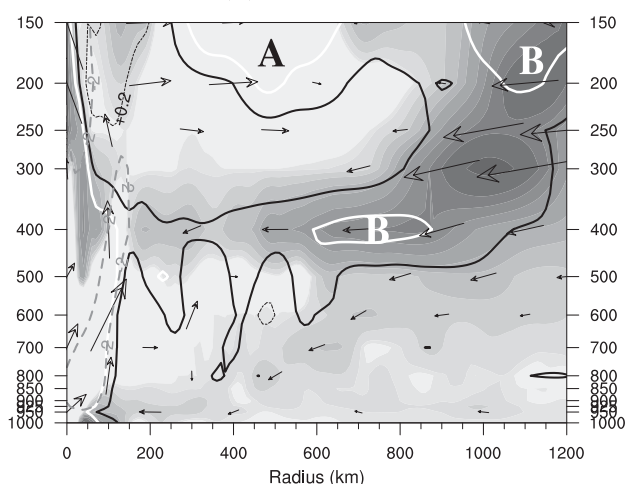

FIG. 8. Radius-pressure cross sections of negative values of PV radial advection ( $-u \mathrm{PV}$; PVU m s${ }^{-1}$, shaded) after (a),(b) 28 and (c),(d) $36 \mathrm{~h}$ of simulation and along (left) $200^{\circ}$ and (right) $160^{\circ}$ azimuth (cross sections are delineated on horizontal maps in Fig. 7). Superimposed are PV contours of $-0.7,-1.5$, and 0.2 PVU. The TC center is located at the left. Arrows represent the radial and vertical $(-10 \times$ omega $)$ wind vectors. Dashed gray contours indicate regions of vertical velocity lower than $-2 \mathrm{~Pa} \mathrm{~s}^{-1}$. Labels $\mathrm{A}$ and $\mathrm{B}$ are as in Fig. 7.

facilitate the poleward evacuation of Dora's outflow. After $24 \mathrm{~h}$, the outflow exceeds $20 \mathrm{~m} \mathrm{~s}^{-1}$ in the downshearright quadrant (at southeast) near the $500-\mathrm{km}$ radius. Upper-level divergence over the storm region consequently increases (not shown), which contributes in outbalancing the detrimental effect of the large ambient shear.

When the trough is at the closest distance from the TC, during the 30-37-h interval (Fig. 7), unusual mean (a) $28 \mathrm{~h}-130^{\circ}$

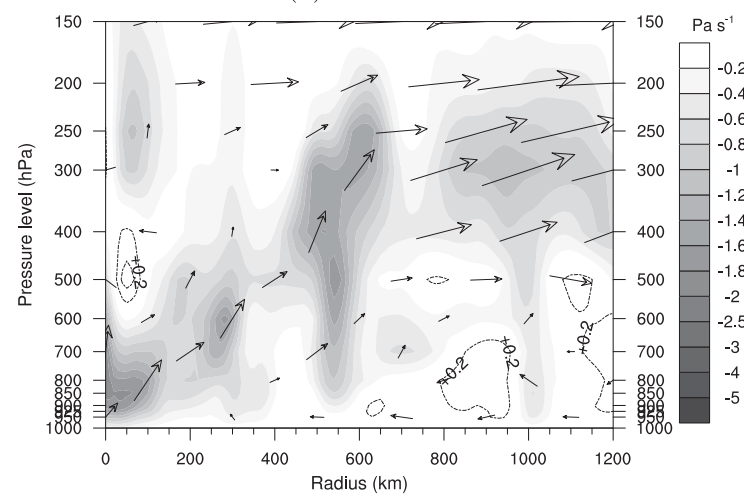

(b) $38 \mathrm{~h}-110^{\circ}$

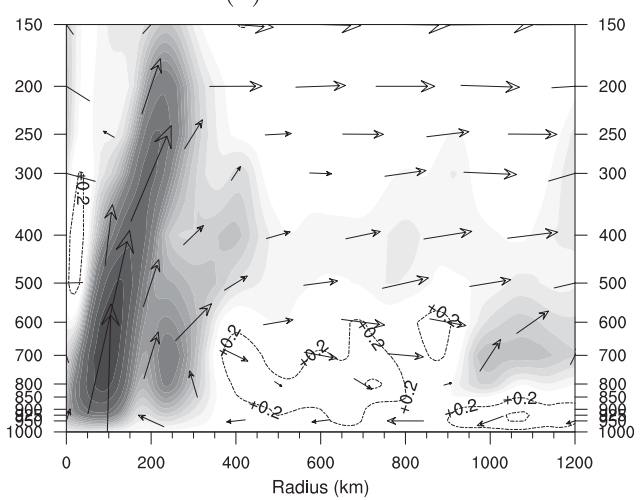

FIG. 9. As in Fig. 8, but for the vertical velocity field ( $\mathrm{Pa} \mathrm{s}^{-1}$; negative, shaded; positive, dotted contours) at (a) 28 and (b) $38 \mathrm{~h}$, in the east-southeastern sector of the storm. 
radial inflow can be found out to $250 \mathrm{~km}$ from the storm center at $200 \mathrm{hPa}$ (Fig. 6b, shaded contours). After $37 \mathrm{~h}$, further inflow from the trough is prevented by enhanced upward motion in the TC core (Fig. 9b) that induces strong divergent storm flow at $200 \mathrm{hPa}$ (Fig. 6b, dotted contours). As expected (Frank and Ritchie 2001) for the Southern Hemisphere where downshear right is equivalent to downshear left in the Northern Hemisphere, large areas of upward motion (and associated convection) are found in the downshear-right quadrant of the storm; they are further enhanced under the left entrance region of the jet stream (Fig. 9). Conversely, subsidence is found in the southern quadrant $\left(170^{\circ}-230^{\circ}\right.$; not shown).

\section{c. Evidence and quantification of $P V$ superposition}

The trough-induced flow enables PV advection from the trough directly into the TC core within a deep tropospheric layer. PV advection results from two tropopause folds. On the northern periphery of the main trough, a first thin and shallow stratospheric intrusion of negative (cyclonic) PV starts penetrating into the troposphere at $8 \mathrm{~h}$ (not shown). At $24 \mathrm{~h}$, it can be seen as a spiral-like filament (Wirth et al. 1997) on the 200-hPa PV map (Fig. 7a, label "A"). Advection toward the TC core first occurs between 26 and $33 \mathrm{~h}$ at $300 \mathrm{hPa}$ (Figs. 8a,b), then between 32 and $37 \mathrm{~h}$ at $200 \mathrm{hPa}$ (Fig. 7c). Negative $\mathrm{PV}$ is also advected downshear away from the TC core (Fig. 7).

The second and major PV advection is associated with the main tropopause fold and extends down to $500 \mathrm{hPa}$ (Figs. 7 and 8, label "B"). At $24 \mathrm{~h}$, the trough or cutofflow core is located about $1000 \mathrm{~km}$ south-southeast of the TC center (Figs. 7a,b). While the strongest PV values associated with $\mathrm{B}$ do not progress much farther toward the TC core at upper levels (Fig. 7a versus Fig. 7c), the folding below reaches the storm center (Fig. $7 \mathrm{~b}$ versus Fig. 7d). Inspection of azimuthal cross sections allows a better understanding of the timing and localization of the PV coherent structure associated with the trough-it is highly tilted toward the equator (Figs. 8b,d). A PV anomaly of smaller size and amplitude detaches from the main trough at midlevels and is advected toward the storm, feeding its core with cyclonic PV between 33 and 40 h (Figs. 8c,d).

The interactions between the trough and the storm PV structures can be quantified by a PV budget in a cylinder that bounds the tropical cyclone. The lateral surface of the cylinder is at a fixed radius from the TC center and the upper and lower surfaces are isentropic levels, which allow us to write the conservative PV budget equation in isentropic and cylindrical coordinates (Haynes and McIntyre 1987):

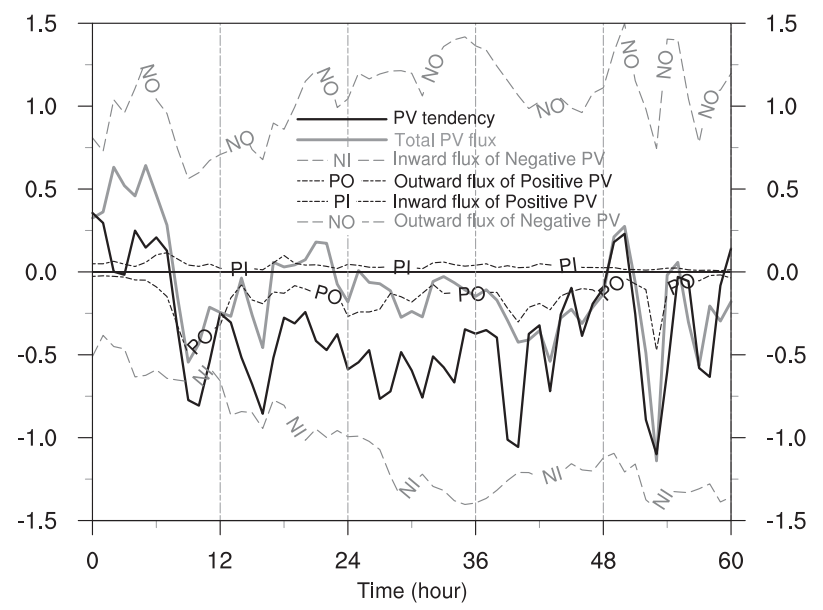

FIG. 10. Time evolution of the PV tendency and PV budget $\left(10^{4} \mathrm{~m}^{5} \mathrm{~K} \mathrm{~s}^{-2} \mathrm{~kg}^{-1}\right)$ computed for a $300-\mathrm{km}$-radius cylinder centered on the TC and located between $305-$ and 350-K theta levels.

$$
\frac{\partial\left(\zeta_{a \theta}\right)}{\partial t}+\nabla \cdot \mathbf{J}=0
$$

where $\nabla$ is the divergence operator in cylindrical and isentropic coordinates; $\theta$ is the potential temperature; $\zeta_{a \theta}=f+\zeta_{\theta}$ is the absolute "isentropic vorticity" (Rossby 1940), which corresponds to the Ertel PV per unit of volume; and $f$ is the Coriolis parameter.

Using Eq. (1) and Stokes's divergence theorem, the volume-integrated PV tendency reduces to the surface integral of the flux terms normal to the volume of interest. The flux of PV (J) has three components (Haynes and McIntyre 1987):

$$
\mathbf{J}=(u, v, 0) \zeta_{a \theta}+\mathbf{J}_{\dot{\theta}}+\mathbf{J}_{F}
$$

The first term on the right-hand side of Eq. (2) is a purely advective flux (horizontal advection and convergence along isentropic surfaces) while the last two contributions are from the local rate of diabatic heating $\mathbf{J}_{\dot{\theta}}$ and from the local frictional force $\mathbf{J}_{F}$ per unit mass. Under adiabatic and frictionless approximations $\left(\mathbf{J}_{\dot{\theta}}\right.$ and $\mathbf{J}_{F}$ are both zero), Eqs. (1) and (2) show that PV is materially conserved along isentropic surfaces.

Figure 10 shows the radial flux $u \zeta_{a \theta}$ across a $300-\mathrm{km}$ radius cylinder bounded by two isentropes at 305 and $350 \mathrm{~K}$ (gray solid line). Low-level $305 \mathrm{~K}$ is chosen high enough to minimize the influence of surface friction. The advective flux is integrated over the cylinder's lateral surface (the base and top of the cylinder do not contribute) and is divided into four components to separate 1) the negative (cyclonic) PV anomalies that are brought into the cylinder ("NI" curve) and 2) the positive PV anomalies that are removed ("PO" curve), which both 
contribute to a negative PV tendency and a spinup of the vortex, as well as 3) the positive PV anomalies that are brought into the cylinder ("PI" curve) and 4) the negative PV anomalies that are removed ("NO" curve), which both contribute to a positive PV tendency and a spindown of the vortex. The volume-integrated PV tendency is calculated using centered differences on the model 1-h outputs (black solid line). It is not easy to directly compute $\mathbf{J}_{F}$ and $\mathbf{J}_{\dot{\theta}}$; these terms can, however, be diagnosed as the difference between the PV tendency and the sum of the advective terms.

Fluxes of negative PV are prevalent in the budget while positive PV fluxes (PI and PO curves) may be neglected (Fig. 10). The first 12-h PV budget can be considered as model spinup. Afterward, negative PV values are advected into the $300-\mathrm{km}$-radius cylinder with a flux that increases between 18 and $36 \mathrm{~h}$ (NI curve). A budget conducted in the 305-335-K layer (not shown) indicates that levels above $335 \mathrm{~K}$ are primarily responsible for this NI trend, with contributions that vary with time depending on the vertical level. This is consistent with cyclonic PV advection from south-southeast to west (Figs. 7 and 8) in relation with the trough approaching the TC center. However, negative (cyclonic) $\mathrm{PV}$ is also exported (NO line), mostly because of outward advection of the TC vorticity in the direction of the vertical shear vector (Fig. 7). The fact that levels below $335 \mathrm{~K}$ contribute to that PV export (not shown) suggests possible outward-propagating vortex Rossby waves during TC intensification. Such waves theoretically propagate radially downgradient along the azimuthally mean PV distribution of the inner-core vortex (Montgomery and Kallenbach 1997).

The two major fluxes evolve quite symmetrically (NI and NO curves) but the total lateral PV flux and the PV tendency overall decrease (Fig. 10). A strong response of the PV tendency is apparent between 38 and $40 \mathrm{~h}, 2 \mathrm{~h}$ after inward negative PV flux maximum. The clear difference between the PV tendency and the total lateral $\mathrm{PV}$ flux prior to $42 \mathrm{~h}$ suggests the presence of nonconservative processes (the $\nabla \cdot \mathbf{J}_{\dot{\theta}}$ and $\boldsymbol{\nabla} \cdot \mathbf{J}_{F}$ fluxes) resulting from diabatic heating and from vertical eddy transport of heat and momentum by unresolved convection [as suggested by Molinari et al. (1998), based on previous studies]. The presence of convective processes is consistent with the trough-induced strong upward motion depicted until $38 \mathrm{~h}$ in the downshear quadrant of the storm at such radii (Fig. 9).

\section{d. Summary of the interaction}

It has been shown that the trough approaching TC Dora gradually deforms and tilts toward the equator at middle levels, allowing cyclonic PV advection toward the TC core in the 500-200-hPa layer, mostly between 24 and $40 \mathrm{~h}$. The TC upper-level anticyclone turns into a cyclonic circulation, and strong upward motion occurs before $42 \mathrm{~h}$ outside of the radius of maximum wind.

Tilting of the coherent structure toward the equator at middle levels is beneficial to the interaction for several reasons. First, the two cyclonic circulations get closer at middle levels where they have equivalent scale and strength (they almost merge at 36 h; Fig. 7d), allowing direct advection of comparable PV values from the trough into the TC core (Fig. 8d). Second, the main trough and associated jet stay at a distance greater than $500 \mathrm{~km}$ from the TC core at upper levels, so that the interaction benefits from large upper-level divergence with fewer vertical wind shear at upper levels, where it has been shown to be the most detrimental (Wang 2012). Once the TC cyclonic circulation and associated convection strengthens, the induced outflow at upper levels prevents further PV advection toward the center (cyclonic PV values spiral at the outskirts of the TC core; Fig. 7e) and the trough goes away rapidly. Though such "PV superposition" was also depicted for Hurricane Elena and Tropical Storm Danny (1985) with large-scale operational analyses (Molinari et al. 1995, 1998), these processes were confined in the upper troposphere. The specificity of Dora is the downward extension of similar phenomena down to the 500-hPa level. A question follows: how can such environmental PV distribution influence the TC circulation and lead to intensification?

\section{A pathway to intensification under upper-level forcing}

\section{a. Horizontal and vertical eddy transport of heat and momentum}

The wave activity of a trough can be viewed as largescale eddy transport of angular momentum, heat (Molinari and Vollaro 1989, 1990), and potential vorticity (Molinari et al. 1995, 1998) that may vary in connection with the previously discussed PV structure evolution. Its impact on the mean tangential flow acceleration can be assessed with Eliassen-Palm (E-P) fluxes (Hartmann et al. 1984).

E-P fluxes are computed in a storm-following cylindrical and isentropic framework for an adiabatic frictionless $f$ plane, following Molinari et al. (1995). The E-P flux vector and its divergence are given respectively by

$$
\begin{aligned}
\mathbf{F}_{L} & \equiv-r \overline{\left(\sigma u_{L}\right)^{\prime} v_{L}^{\prime}} \overline{p^{\prime} \Psi_{\lambda}^{\prime}}, \\
\nabla \cdot \mathbf{F}_{L} & =-r^{-1}\left[r^{2} \overline{\left(\sigma u_{L}\right)^{\prime} v_{L}^{\prime}}\right]_{r}+\left(\overline{p^{\prime} \Psi_{\lambda}^{\prime}}\right)_{\theta},
\end{aligned}
$$

where subscripts $L$ indicate storm-relative flow; all other subscripts represent derivatives; $u$ and $v$ are the radial 
(a) $0-5 \mathrm{~h}$

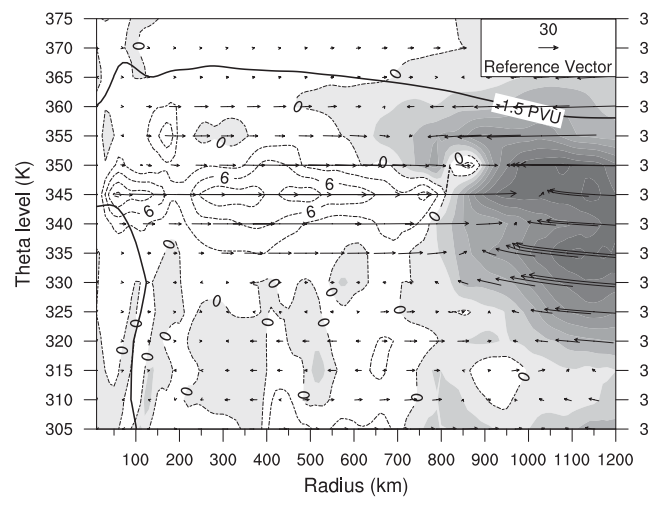

(c) $36-41 \mathrm{~h}$

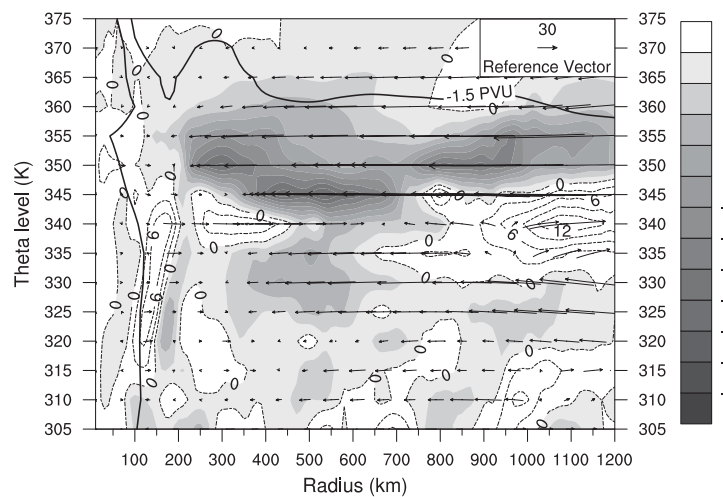

(b) $24-29 \mathrm{~h}$

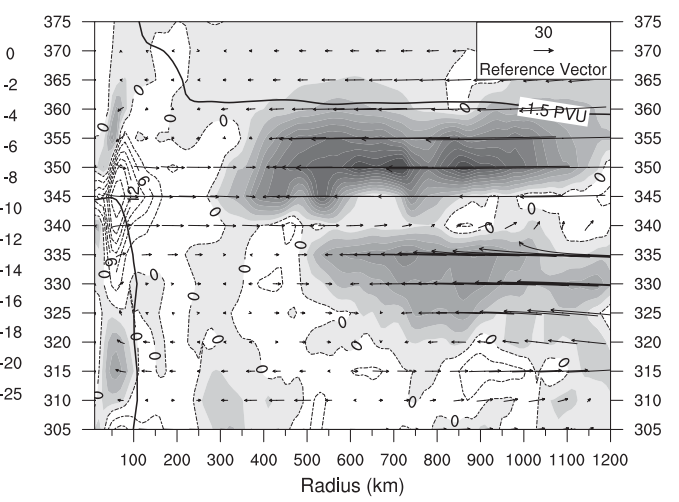

(d) $44-49 \mathrm{~h}$

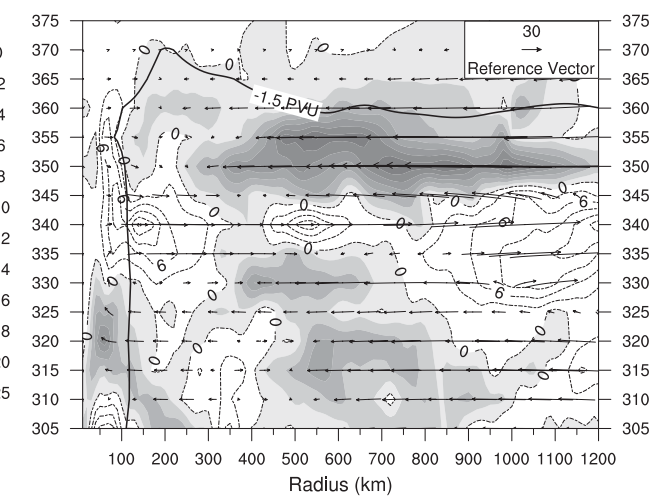

FIG. 11. Radius-theta cross sections of E-P flux vectors and their divergence (negative, shaded; positive, dotted contours at $0,3,6,9,12,15$, and $20 \times 10^{4} \mathrm{~Pa} \mathrm{~m}^{2} \mathrm{~K}^{-1} \mathrm{~s}^{-2}$ ) averaged over 5-h intervals as indicated above each panel. The horizontal (vertical) arrow scale is $1.3 \times 10^{8} \mathrm{~Pa} \mathrm{~m}^{3} \mathrm{~K}^{-1} \mathrm{~s}^{-2}\left(9.3 \times 10^{2} \mathrm{~Pa} \mathrm{~m}^{2} \mathrm{~s}^{-2}\right)$ for $\mathbf{F}_{r}\left(\mathbf{F}_{v}\right)$, following Edmon et al. (1980) scaling that consists of multiplying the numerical values of $\mathbf{F}_{r}$ and $\mathbf{F}_{v}$ by the distances occupied by $1 \mathrm{~m}$ and $1 \mathrm{~K}$ on the figure, respectively. A solid line indicates the azimuthal-mean altitude of the dynamic tropopause ( -1.5 -PVU surface).

and tangential velocity components, respectively; $\Psi$ is the Montgomery streamfunction $\left(\Psi=\Phi+C_{p} T\right.$, where $\Phi$ is the geopotential); $\sigma \equiv-p_{\theta}$ is the pseudodensity; an overbar represents azimuthal average; a prime indicates a deviation from the azimuthal average; and $\nabla$ is the two-dimensional (radial and vertical) derivative operator.

The first (radial) component of the E-P vector $\mathbf{F}_{r}$ is the angular momentum flux; the second (vertical) vector $\mathbf{F}_{v}$ is the eddy heat flux. For E-P flux diagrams in the Southern Hemisphere, an inward-pointing vector $\left(\mathbf{F}_{r}<\right.$ $0)$ represents an inward eddy flux of cyclonic angular momentum. A downward-pointing vector $\left(\mathbf{F}_{v}<0\right)$ represents a source of eddy heat flux. The E-P flux divergence $\boldsymbol{\nabla} \cdot \mathbf{F}_{L}$ (scalar contours) summarizes the impact of both eddy angular momentum and eddy heat fluxes on the mean (pseudodensity weighted) relative angular momentum [Eq. (1) of Molinari et al. (1995)]. In short, the mean azimuthal flow adjusts to the total eddy forcing. When $\boldsymbol{\nabla} \cdot \mathbf{F}_{L}<0$ (E-P flux convergence), eddy activity is increasing cyclonic mean angular momentum, which spins up a cyclonic circulation but spins down an anticyclonic circulation with mean-to-eddy transfer of energy (Molinari et al. 1995). On the contrary, E-P flux divergence $\left(\boldsymbol{\nabla} \cdot \mathbf{F}_{L}>0\right)$ is associated with the spinup of a preexistent upper-level anticyclonic circulation.

E-P flux diagrams integrated over 5-h intervals clearly show the progression of the trough and its impact on Dora's circulation (Fig. 11). The dynamic tropopause, defined as the $-1.5 \mathrm{PV}$ unit (PVU) surface, is generally located at $150 \mathrm{hPa}$ (about $360 \mathrm{~K}$ ). At the beginning of the simulation (Fig. 11a), the trough imports cyclonic eddy angular momentum (inward arrows with convergence) over a thick layer $(315-370 \mathrm{~K})$ outside the $700-\mathrm{km}$ radius. Upward eddy heat fluxes located just below the trough $(325-335 \mathrm{~K})$ are associated with residual baroclinic instability within the synoptic wave from the midlatitudes. Ahead of the trough, acceleration of the mean outflow anticyclone is visible (dotted contours) with outward fluxes of angular momentum between 330 and $365 \mathrm{~K}$. Fluxes penetrate inside $400 \mathrm{~km}$ after $24 \mathrm{~h}$ (Fig. 11b), as Dora and the trough begin to interact (section 3 ). They produce 
(a) $\mathrm{d} \bar{v} / \mathrm{dt}$ at $700 \mathrm{hPa}$

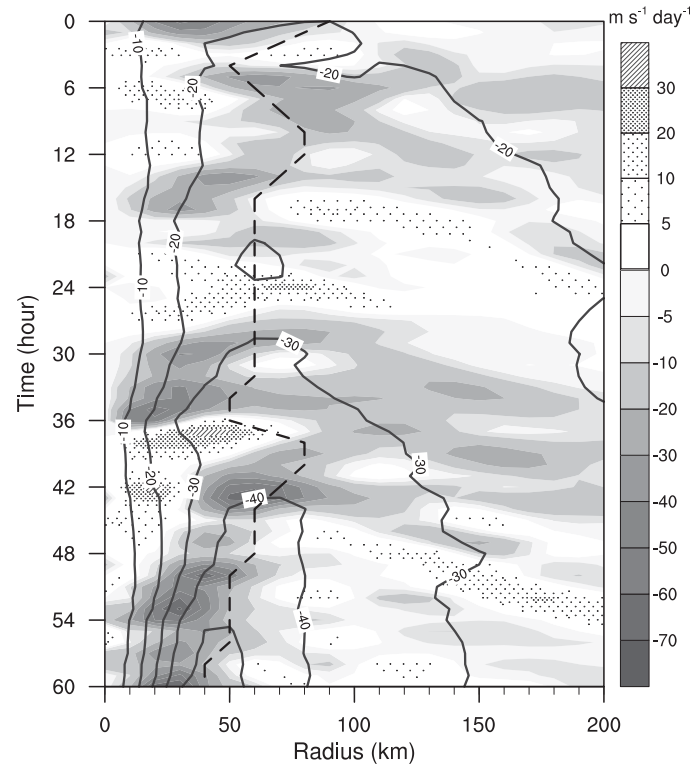

(b) $\bar{\omega}$ at $500 \mathrm{hPa}$

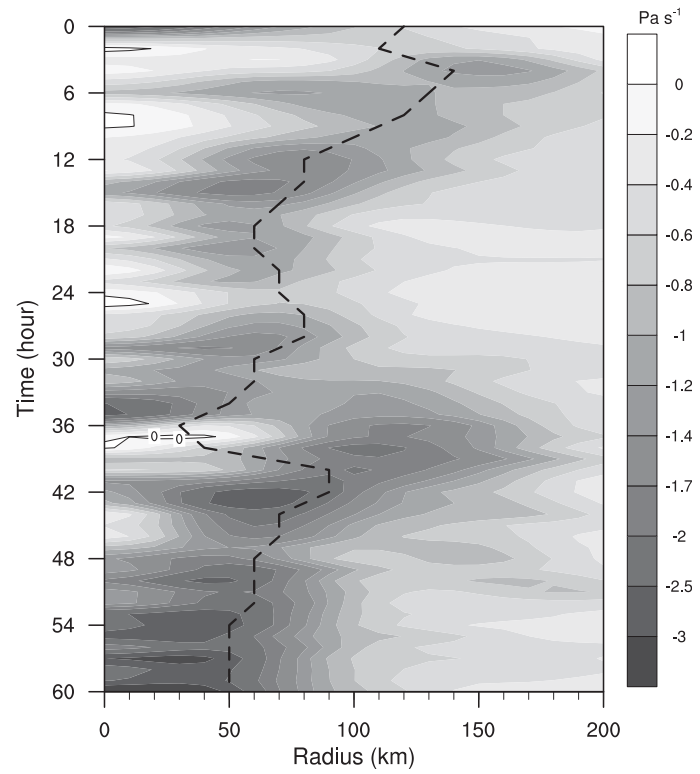

FIG. 12. Radius-time plots of (a) 700-hPa azimuthal-mean tangential wind tendency ( $\mathrm{m} \mathrm{s}^{-1} \mathrm{day}^{-1}$; negative, shaded; positive, hatched) and (b) 500-hPa azimuthal-mean vertical velocity ( $\mathrm{Pa} \mathrm{s}^{-1}$; negative, shaded; positive, zero contour). Dashed lines indicate the radius of maximum cyclonic (negative) mean tangential wind at the corresponding pressure levels. Solid contours in (a) show the azimuthal-mean wind $\left(\mathrm{m} \mathrm{s}^{-1}\right)$ at $700 \mathrm{hPa}$.

increasing cyclonic mean tangential wind and can explain the decay of the mean outflow anticyclone. Although the trough signature has suffered vertical splitting due to tropopause folding and PV stretching at middle levels (section 3), inward fluxes of angular momentum are still observed down to $320 \mathrm{~K}$. A strip of convergence can be seen at the leading edge of the main convergence zone; it is tilted toward the trough and contributes to angular momentum spinup over the radial range $250-350 \mathrm{~km}$. It is part of the trough forcing and is materialized by an outward-tilted asymmetric convective band located downshear, associated with the strong upward motion previously depicted in the downshear-right quadrant of the storm (Fig. 9).

After $36 \mathrm{~h}$ (Fig. 11c), the TC core cyclonic circulation has extended to upper levels as a consequence of the continuous import of cyclonic angular momentum after $24 \mathrm{~h}$. Wave activity is now located within $100-\mathrm{km}$ radius of the storm center at upper levels where the TC inertial stability is the lowest. Eddy heat fluxes remain small at all levels, suggesting that barotropic processes prevail. Between 36 and $41 \mathrm{~h}$, cyclonic forcing is found outside the eyewall at 100-200-km radii (Fig. 11c, shaded strip), with weakening inside an averaged $100-\mathrm{km}$ radius (dotted contours) - note that from 36 to $39 \mathrm{~h}$, the weakening occurs near $50-\mathrm{km}$ radius. Cyclonic spinup extends throughout the entire troposphere, from the trough down to the lowest level, which differs from the results of previous studies (e.g., Molinari et al. 1995). The trough leads to the intensification of the outer part of the storm, while the inner eyewall is forced to spin down. In addition, radius-time series of eddy PV fluxes [right-hand-side term of Eq. (2b) in Molinari et al. (1995)] confirm the role of eddy vorticity fluxes in increasing the tangential wind speed at the 335- and 355-K theta levels (not shown) during the 36-42-h period, in connection with maximum PV tendency and lateral PV flux (Fig. 10).

After $44 \mathrm{~h}$ (Fig. 11d), trough interaction is over in terms of wave forcing. The strongest eddy activity is propagating outward and lessens as the distance between Dora and the trough increases. The cyclonic circulation increases inside $100 \mathrm{~km}$ for a few more hours, in association with main eyewall intensification.

\section{b. Eyewall replacement cycle}

E-P flux analysis suggests that, by intensifying eddy momentum flux convergence and eddy PV fluxes in the vicinity of the storm, the trough might have forced an eyewall replacement cycle between 36 and $41 \mathrm{~h}$. The evolution of the radius of maximum winds at $850 \mathrm{hPa}$ (not shown) and aloft (Figs. 12a,b) confirms the signature of an ERC. A first intensification period occurs between 33 and $36 \mathrm{~h}$ (Figs. 4 and 12a) while the inner eyewall contracts from about 50 to $40 \mathrm{~km}$ at $850 \mathrm{hPa}$. At $36 \mathrm{~h}$, the azimuthal-mean tangential wind shows an inner maximum over a deep layer with mean upward velocities 
(a) $36 \mathrm{~h}$

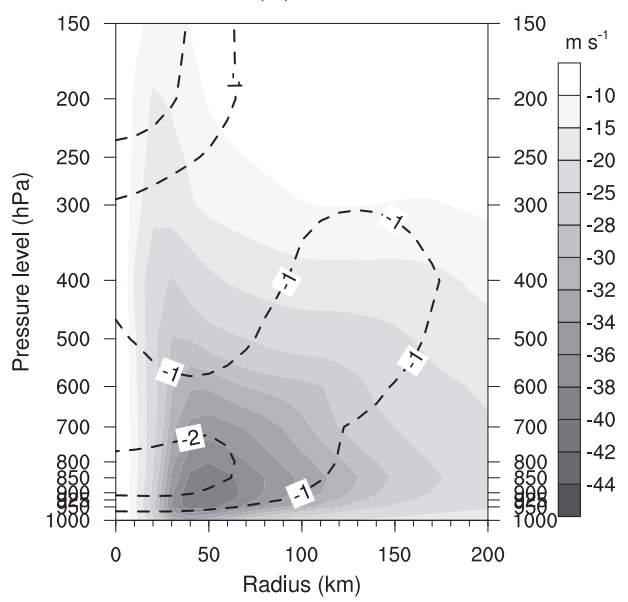

(b) $38 \mathrm{~h}$

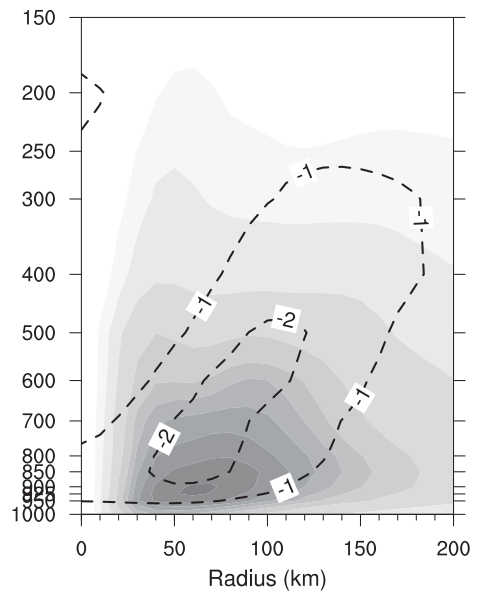

(c) $44 \mathrm{~h}$

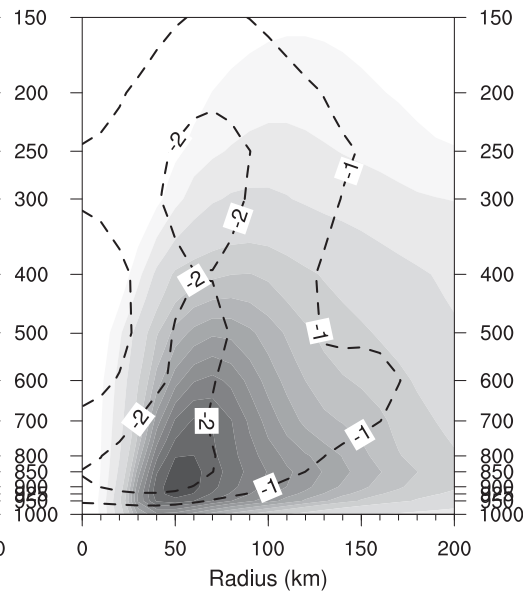

FIG. 13. Radius-pressure plots of azimuthal-mean tangential wind ( $\mathrm{m} \mathrm{s}^{-1}$; shaded) at (a) 36, (b) 38, and (c) $44 \mathrm{~h}$. Dashed lines indicate vertical velocity contours of -1 and $-2 \mathrm{~Pa} \mathrm{~s}^{-1}$.

starting to tilt outward under upper-level trough forcing (Fig. 13a). The outward expansion of the wind field that is visible in Figs. 12a and 13a should increase the efficiency of tangential wind spinup in any outer region with latent heating (Rozoff et al. 2012).

A secondary wind maximum then develops in the low to middle troposphere between 36 and $40 \mathrm{~h}$ around $80 \mathrm{~km}$ (Fig. 13b). At $850 \mathrm{hPa}$, contraction of this outer eyewall from 80 to $50 \mathrm{~km}$ between 41 and $44 \mathrm{~h}$ is associated with a rapid intensification of the maximum mean tangential wind (Fig. 4). Symmetric intensification associated with eyewall contraction is found throughout the troposphere up to $300 \mathrm{hPa}$ (e.g., Fig. 12a at $700 \mathrm{hPa}$ ). Between the occurrences of the primary inner wind maximum and the secondary outer wind maximum (from 36 to $41 \mathrm{~h}$ ), the maximum mean wind decreases or stagnates (Figs. 4 and 12a). Such a signature is characteristic of an ERC (Shapiro and Willoughby 1982; Willoughby et al. 1982). It is correlated with an outward shift of the maximum upward velocities and associated convection (Fig. 12b): At $36 \mathrm{~h}$, a primary region of strong upward motion is visible inside the primary eyewall, while a second convective region is intensifying 100$150 \mathrm{~km}$ away from the vortex center. Afterward, subsidence appears again in the inner-core region and outer convection moves inward toward the radius of maximum wind (Figs. 9b, 12b, and 13c), resembling the contraction of the secondary eyewall in ERCs.

While the diagnosed eyewall replacement cycle is consistent with angular momentum import and vertical velocity forcing from the trough, the interpretation of E-P fluxes under the adiabatic assumption can be questioned in the TC inner-core region where diabatic processes are involved. The purpose of the following section is therefore to use a complementary method without adiabatic approximation in order to confirm the trough contribution to $\mathrm{TC}$ intensification.

\section{c. Tangential wind budget}

A tangential wind budget is computed in a stormfollowing cylindrical framework on pressure coordinates following Persing et al. (2002):

$$
\begin{aligned}
\frac{\partial \bar{v}_{L}}{\partial t}= & \left(-\bar{u}_{L} \bar{\zeta}_{a}\right)+\left(-\overline{u_{L}^{\prime} \zeta_{a}^{\prime}}\right)+\left(-\bar{\omega} \frac{\partial \bar{v}_{L}}{\partial p}\right) \\
& +\left(-\overline{\omega^{\prime} \frac{\partial v_{L}^{\prime}}{\partial p}}\right)+\text { Friction },
\end{aligned}
$$

where $\omega$ is the vertical pressure velocity and $\zeta_{a}$ the vertical absolute vorticity. Friction is not taken into account here.

The first four terms on the right-hand side of Eq. (5) are, from left to right, the horizontal vorticity fluxes by the mean flow (MVF) and by the eddies (EVF) and the vertical advection of the tangential wind by the mean flow (MVA) and by the eddies (EVA). Vertical cross sections of these four terms, integrated over 4-h intervals, are displayed at 26-30 and 37-41 h (Figs. 14 and 15). Although local tendencies of the mean tangential wind estimated from the model output using central differences (e.g., Fig. 14f) are affected by numerical filtering and other numerical procedures, they compare well with the sum of the four terms of the budget equation without friction (e.g., Fig. 14c). Contributions from the mean flow (MVA and MVF terms) have about the same magnitude but opposite signs before the trough moves into the volume (Fig. 14). Overall, the MVF tends 
(a) $\mathrm{MVF}=-\bar{u}_{L} \bar{\zeta}_{a}$

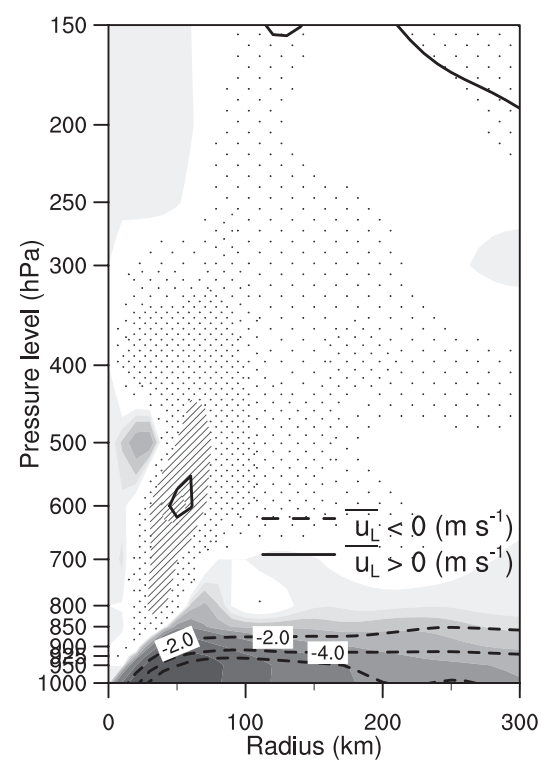

(d) $\mathrm{EVF}=-\overline{u_{L}^{\prime} \zeta_{a}^{\prime}}$

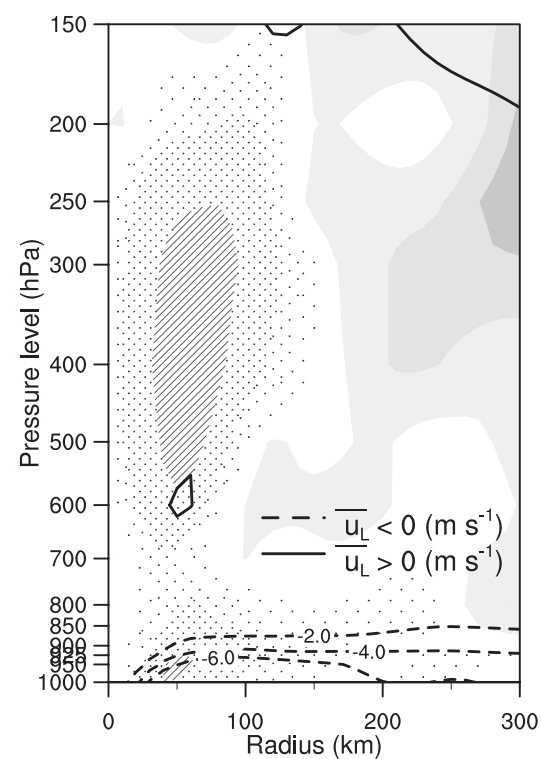

(b) $\mathrm{MVA}=-\bar{\omega} \frac{\partial \bar{v}_{L}}{\partial p}$

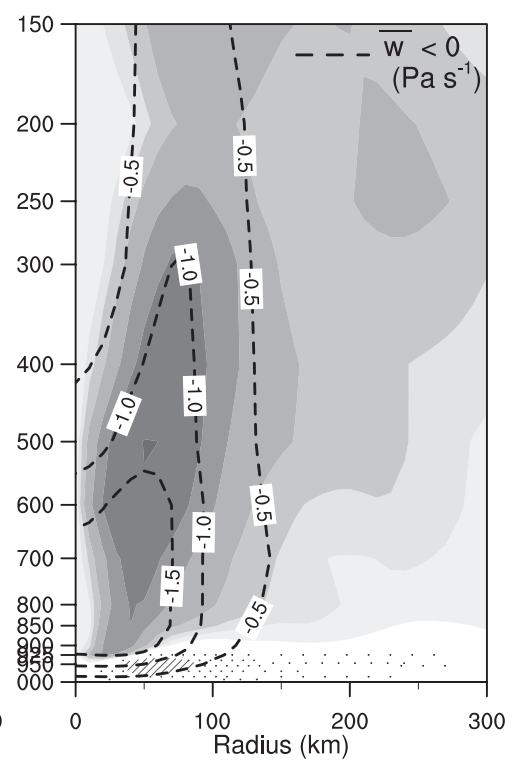

(e) $\mathrm{EVA}=-\overline{\omega^{\prime} \frac{\partial v_{L}^{\prime}}{\partial p}}$

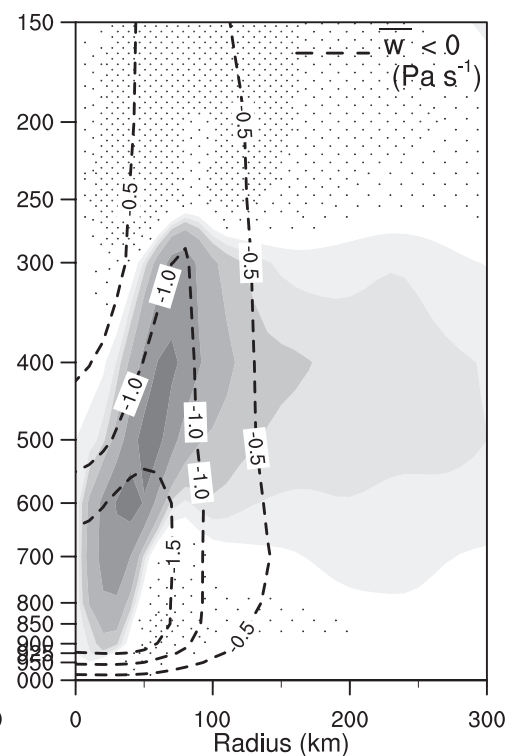

(c) SUM

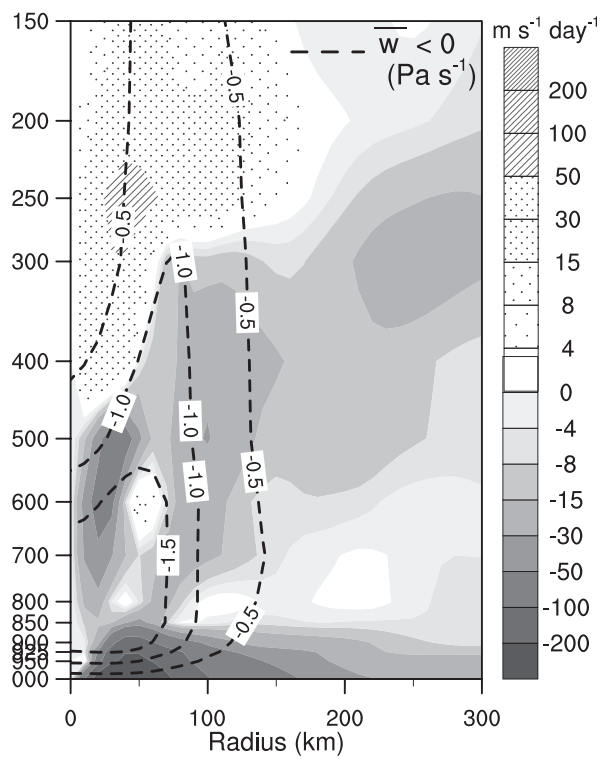

(f) $\mathrm{d} \bar{v}_{L} / \mathrm{dt}$

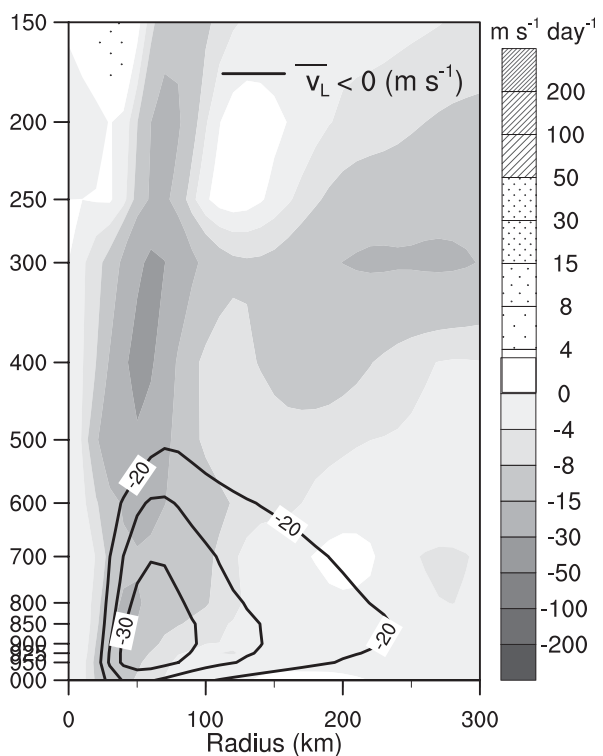

FIG. 14. Radius-pressure cross sections of the four terms of the mean tangential wind budget ( $\mathrm{m} \mathrm{s}^{-1}$ day $^{-1}$; negative, shaded; positive, hatched) averaged between 26 and $30 \mathrm{~h}$. (a) MVF and (d) EVF are the mean and eddy vorticity flux, respectively; (b) MVA and (e) EVA are the mean and eddy vertical advection, respectively; (c) SUM represents the sum of the previous four terms; and (f) is the mean tangential wind tendency computed for comparison. Superimposed are contours of the azimuthal-mean radial wind, tangential wind, or vertical velocity.

to slow down the mean cyclonic circulation of the eyewall region above the boundary layer (Fig. 14a), whereas the MVA acts to accelerate it (Fig. 14b). The eddy terms EVF and EVA (Figs. 14d,e) are of smaller amplitude. Considerable differences appear however once the trough penetrates within a radius of $300 \mathrm{~km}$.

The wind starts to increase at the periphery of the TC $(200-300 \mathrm{~km})$ after $26 \mathrm{~h}$ (Figs. 14c,f) in correlation with eddy vorticity fluxes (Fig. 14d). This contribution is similar to cyclonic eddy momentum import throughout the troposphere at such radii (Fig. 11b) and explains the spindown of the preexistent anticyclonic circulation near $200 \mathrm{hPa}$. The close proximity of the trough is obvious between 37 and $41 \mathrm{~h}$ (Fig. 15): vorticity flux by the mean flow (MVF) enhances the cyclonic circulation between 200 and $500 \mathrm{hPa}$ in the inner core where radial 
(a) $\mathrm{MVF}=-\bar{u}_{L} \bar{\zeta}_{a}$

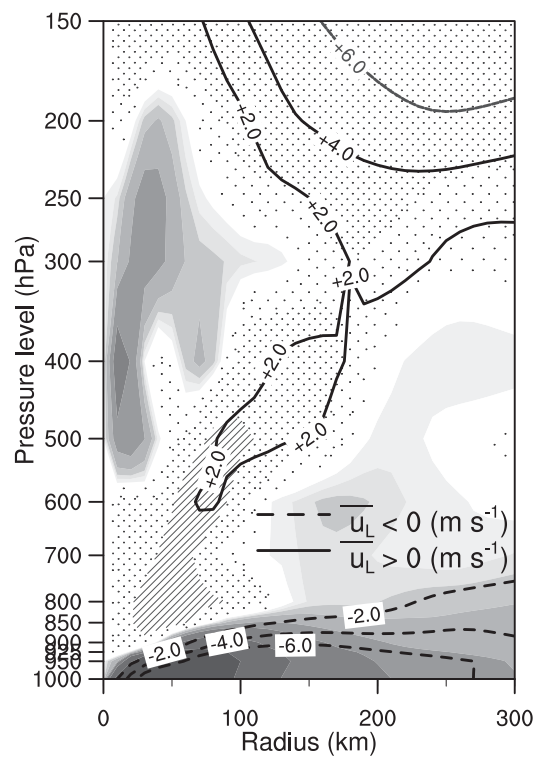

(d) $\mathrm{EVF}=-\overline{u_{L}^{\prime} \zeta_{a}^{\prime}}$

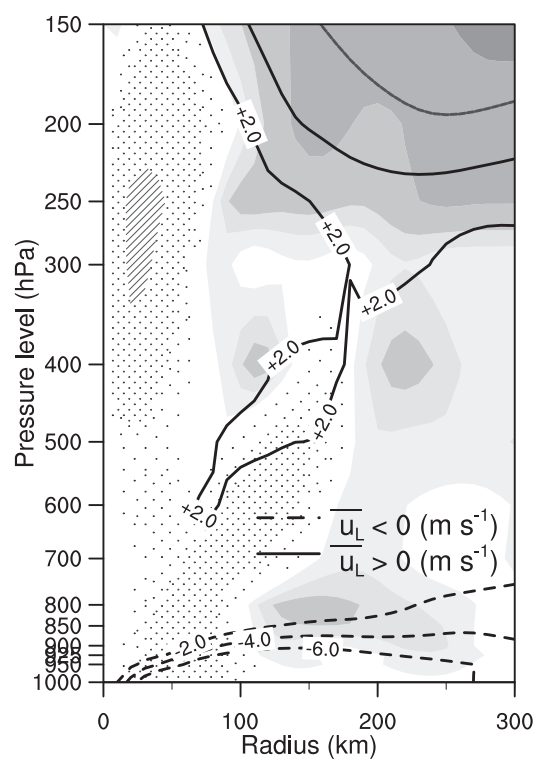

(b) $\mathrm{MVA}=-\bar{\omega} \frac{\partial \bar{v}_{L}}{\partial p}$

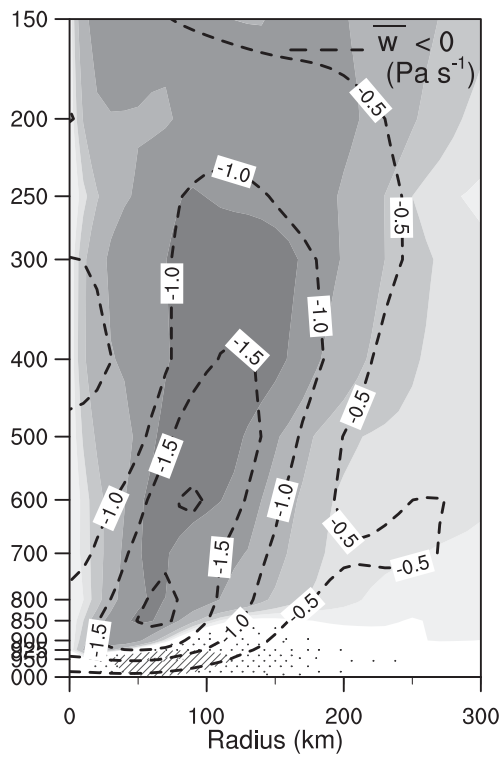

(e) $\mathrm{EVA}=-\overline{\omega^{\prime} \frac{\partial v_{L}^{\prime}}{\partial p}}$

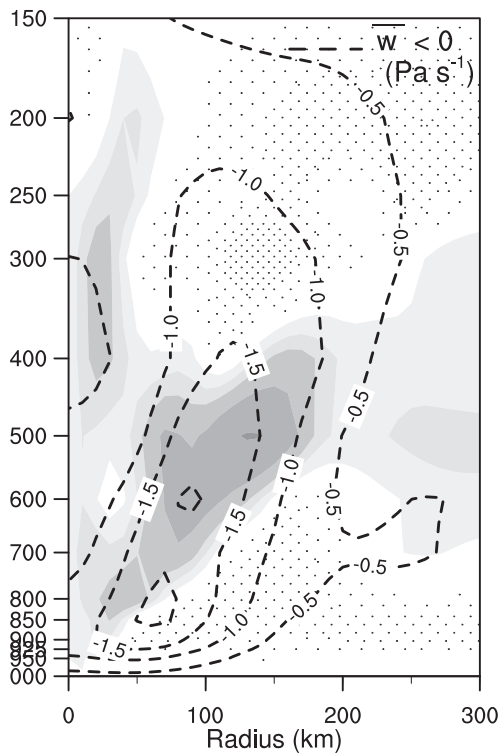

(c) SUM

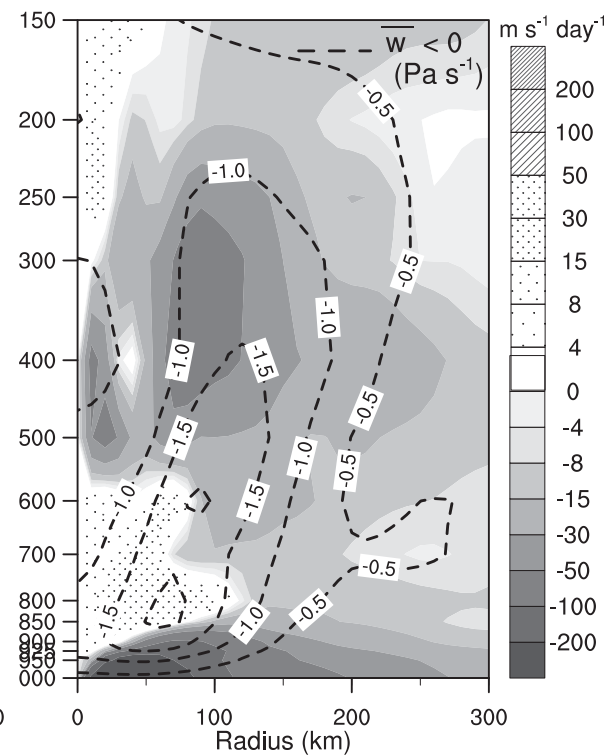

(f) $\mathrm{d} \bar{v}_{L} / \mathrm{dt}$

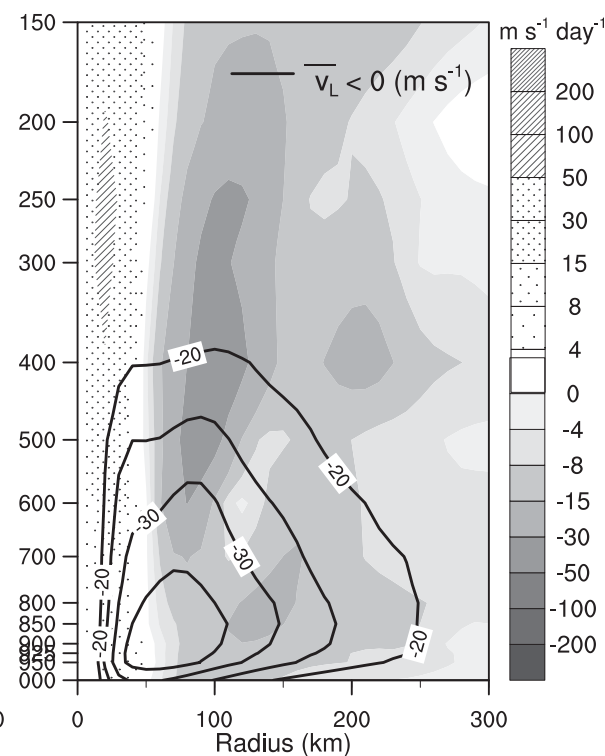

FIG. 15. As in Fig. 14, but from 37 to $41 \mathrm{~h}$.

inflow has appeared (Fig. 6b). Forcing by the eddies (EVF) occurs almost over the whole troposphere inside a 150-300-km-radius range. Besides, both MVF (mainly) and EVF (marginally) contribute to the spindown of the primary eyewall (Figs. 15a,d,c,f) that is visible within $50-\mathrm{km}$ radii in Fig. 12. This confirms and extends the conclusions deduced from the E-P fluxes (section 4a). These results also indicate that the asymmetric PV advection previously seen in cross sections (Figs. 8c,d) has a mean-azimuthal signature (MVF) that contributes to upper-level vortex intensification (Fig. 15a). The MVF term is also responsible for cyclonic vorticity advection in the boundary layer where converging flow has increased.

Convective updrafts (Fig. 15b, dotted contours) start tilting outward at $37 \mathrm{~h}$, together with the radial outflow channel of the eyewall (Fig. 15a, solid contours). This tilting is due to the dynamics induced by the troughthat is, the evolution of the PV intrusion that forces upward motion at its leading edge (Figs. 8 and 9). From the top of the boundary layer up to $400 \mathrm{hPa}$, vertical 
advection of the tangential wind by the eddies and by the mean flow is responsible for cyclonic spinup near 100-km radius, where environmentally forced upward velocities are maximum (Figs. 15b,e and 12b). Contours of the mean tangential wind start showing a double-peaked structure, with a second maximum developing outside (Fig. 15f, solid contours).

As the trough moves away from the storm after $42 \mathrm{~h}$, the forcing disappears and the TC becomes vertically aligned again: a single branch of strong upward motion extends through the whole troposphere as the TC has intensified (Fig. 13c, dashed lines). The outer eyewall has replaced the main eyewall (Figs. 12a and 13c) and its radius has already contracted to $50 \mathrm{~km}$ at the top of the boundary layer.

\section{Discussion and conclusions}

The rapid intensification of TC Dora (2007) in the southwest Indian Ocean in the vicinity of an upper-level trough that imposed long-lasting strong vertical wind shear has been investigated. It has been found that the trough and associated three-dimensional PV coherent structure played a significant role in the storm's intensification and eyewall replacement cycle through various coupled processes.

The initial anticyclonic circulation above Dora, along with the strong downward motions associated with the initial Rossby wave breaking event, favored equatorward tilting of the trough and the detachment of a spirallike filament of PV at upper levels ahead of the trough. Such a configuration with the main upper-level trough core and associated jet at a reasonable distance from the TC increased upper-level divergence while preventing the most destructive part of the shear to affect the storm. The trough imposed a strongly asymmetric cross-storm flow over a thick 500-200-hPa layer, allowing cyclonic $\mathrm{PV}$ advection toward the TC core in the southwestern quadrant for about $15 \mathrm{~h}$.

Once the coherent structure entered the $300-\mathrm{km}$ radius volume, eddy horizontal flux of vorticity, as well as eddy vertical advection (associated with asymmetric convection in the downshear-right quadrant, dynamically enhanced under the left entrance region of the upper-level jet), caused an outward expansion of the cyclonic winds in the 850-200- and 850-400-hPa layers, respectively. When the coherent structure was at its closest distance from the storm, cyclonic spinup was first observed inside the eyewall as a result of PV superposition (vorticity fluxes by the mean flow) in the $500-200-\mathrm{hPa}$ layer, where unusual mean radial inflow was observed. Vertical velocity and deep convection increased inside the radius of maximum wind in association with a short period of rapid intensification, in agreement with Nolan et al. (2007) and Vigh and Schubert (2009) theories.

Unlike storms from previous studies that rapidly intensified in strong vertical wind shear, intense convection in Dora shifted outward during the following $6 \mathrm{~h}$. Eddy angular momentum convergence and eddy PV (or absolute vorticity) fluxes intensified just outside the radius of maximum wind (inside a 100-150-km annulus) over the entire troposphere, and were also responsible for spinning down the primary eyewall. This led to the formation of an outer eyewall, which intensified further through mean vertical advection within the highly tilted environmentally forced upward motion. Trough forcing therefore triggered an eyewall replacement cycle, which was responsible for the following rapid intensification during a 6-h period due to secondary eyewall contraction. The ERC was observed for Dora around the same time as in the simulation, suggesting that it is not an artifact from the Aladin model and that secondary eyewall formation can be simulated by a hydrostatic model with moderate horizontal resolution and parameterized convection.

Although based on a particular storm, this study gives some insight on the pathway to storm intensification through upper-level forcing. The main mechanisms identified for vortex intensification are PV superposition (associated with angular momentum convergence), followed by secondary eyewall formation induced by eddy momentum flux convergence, eddy PV (or absolute vorticity) fluxes, and vertical velocity forcing from the trough, which contributed to mean and eddy vertical advection of the tangential wind in the outer eyewall. These results confirm the speculations of Molinari and Vollaro (1989) and the idealized simulations of Nong and Emanuel (2003), although with the use of a realistic evolving distribution of forcing. We have explained how an upper-level trough can induce cyclonic spinup over the whole troposphere at outer radii. PV advection was found to occur at midlevels, which also differs from previous studies.

Another interesting aspect that has not yet been described is the evolution of the radial PV distribution in the inner-core region at midlevels, which could cause the downgradient propagation of vortex Rossby waves as observed at low-levels near the radius of maximum wind (Qiu et al. 2010; Abarca and Corbosiero 2011; Nguyen et al. 2011; Corbosiero et al. 2012). The role of such waves in connecting core dynamics and external forcing over the entire troposphere shall be reported in a future study. The sensitivity of the interaction to the respective positions and strengths of the TC and the trough will also be assessed. 
Acknowledgments. The authors thank the MAIF foundation for cosponsoring this project. The authors are indebted to Ghislain Faure for his precious help on modeling aspects. The two anonymous reviewers are thanked for their constructive remarks.

\section{REFERENCES}

Abarca, S. F., and K. L. Corbosiero, 2011: Secondary eyewall formation in WRF simulations of Hurricanes Rita and Katrina (2005). Geophys. Res. Lett., 38, L07802, doi:10.1029/ 2011 GL047015.

Bosart, L. F., W. E. Bracken, J. Molinari, C. S. Velden, and P. G. Black, 2000: Environmental influences on the rapid intensification of Hurricane Opal (1995) over the Gulf of Mexico. Mon. Wea. Rev., 128, 322-352.

Corbosiero, K. L., S. Abarca, and M. T. Montgomery, 2012: Vortex Rossby waves and secondary eyewall formation in a high-resolution simulation of Hurricane Katrina (2005). Preprints, 30th Conf. on Hurricanes and Tropical Meteorology, Ponte Vedra Beach, FL, Amer. Meteor. Soc. [Available online at https://ams.confex.com/ams/30Hurricane/webprogram/ Paper205787.html.]

Davidson, N. E., C. M. Nguyen, and M. Reeder, 2008: Downstream development during the rapid intensification of hurricanes Opal and Katrina: The distant trough interaction problem. Preprints, 28th Conf. on Hurricanes and Tropical Meteorology, Orlando, FL, Amer. Meteor. Soc., 9B.4. [Available online at https://ams.confex.com/ams/28Hurricanes/techprogram/ paper_138060.htm.]

DeMaria, M., J. Kaplan, and J.-J. Baik, 1993: Upper-level eddy angular momentum fluxes and tropical cyclone intensity change. J. Atmos. Sci., 50,1133-1147.

Duvel, J.-P., C. Basdevant, H. Bellenger, G. Reverdin, A. Vargas, and J. Vialard, 2008: The Aeroclipper: A new device to explore convective systems and cyclones. Bull. Amer. Meteor. Soc., 90, 63-71.

Edmon, H. J., B. J. Hoskins, and M. E. McIntyre, 1980: EliassenPalm cross sections for the troposphere. J. Atmos. Sci., 37, 2600-2616.

Emanuel, K. A., 1986: An air-sea interaction theory for tropical cyclones. Part I: Steady-state maintenance. J. Atmos. Sci., 43, 585-604.

Frank, W., and E. Ritchie, 2001: Effects of vertical wind shear on the intensity and structure of numerically simulated hurricanes. Mon. Wea. Rev., 129, 2249-2269.

Franklin, J. L., cited 2008: National Hurricane Center forecast verification. NOAA Rep. [Available online at http://www.nhc. noaa.gov/verification.]

Gadoury, J., and M. K. Yau, 2012: Impact of numerical grid spacing and time step on vortex Rossby-waves in secondary eyewall formation in Hurricane Wilma (2005). Preprints, 30th Conf. on Hurricanes and Tropical Meteorology, Ponte Vedra Beach, FL, Amer. Meteor. Soc. [Available online at https://ams.confex. com/ams/30Hurricane/webprogram/Paper205410.html.]

Hanley, D., J. Molinari, and D. Keyser, 2001: A composite study of the interactions between tropical cyclones and upper-tropospheric troughs. Mon. Wea. Rev., 129, 2570-2584.

Hartmann, D. L., C. R. Mechoso, and K. Yamazaki, 1984: Observations of wave-mean flow interaction in the Southern Hemisphere. J. Atmos. Sci., 41, 351-362.
Haynes, P. H., and M. E. McIntyre, 1987: On the evolution of vorticity and potential vorticity in the presence of diabatic heating and frictional and other forces. J. Atmos. Sci., 44, 828841.

Hendricks, E. A., M. T. Montgomery, and C. A. Davis, 2004: The role of vortical hot towers in the formation of Tropical Cyclone Diana (1984). J. Atmos. Sci., 61, 1209-1232.

—, W. H. Schubert, R. K. Taft, H. Wang, and J. P. Kossin, 2009: Life cycles of hurricane-like vorticity rings. J. Atmos. Sci., 66, 705-722.

_ M. S. Peng, B. Fu, and T. Li, 2010: Quantifying environmental control on tropical cyclone intensity change. Mon. Wea. Rev., 138, 3243-3271.

Holland, G. J., 1980: An analytic model of the wind and pressure profiles in hurricanes. Mon. Wea. Rev., 108, 1212-1218.

Hoskins, B. J., M. E. McIntyre, and A. Robertson, 1985: On the use and significance of isentropic potential vorticity maps. Quart. J. Roy. Meteor. Soc., 111, 877-946.

Huffman, G. J., and Coauthors, 2007: The TRMM Multisatellite Precipitation Analysis (TMPA): Quasi-global, multiyear, combined-sensor precipitation estimates at fine scales. $J$. $\mathrm{Hy}$ drometeor., 8, 38-55.

Kaplan, J., and M. DeMaria, 2003: Large-scale characteristics of rapidly intensifying tropical cyclones in the North Atlantic basin. Wea. Forecasting, 18, 1093-1108.

$\_,-$_ intensification index for the Atlantic and eastern North Pacific basins. Wea. Forecasting, 25, 220-241.

Kossin, J. P., and W. H. Schubert, 2001: Mesovortices, polygonal flow patterns, and rapid pressure falls in hurricane-like vortices. J. Atmos. Sci., 58, 2196-2209.

Lin, I. I., C. C. Wu, K. A. Emanuel, I. H. Lee, C. R. Wu, and I. Pun, 2005: The interaction of Supertyphoon Maemi (2003) with a warm ocean eddy. Mon. Wea. Rev., 133, 2635-2649.

Molinari, J., and D. Vollaro, 1989: External influences on hurricane intensity. Part I: Outflow layer eddy momentum fluxes. J. Atmos. Sci., 46, 1093-1105.

- , and -1990 : External influences on hurricane intensity. Part II: Vertical structure and response of the hurricane vortex. J. Atmos. Sci., 47, 1902-1918.

- , and -2010 : Rapid intensification of a sheared tropical storm. Mon. Wea. Rev., 138, 3869-3885.

—_, S. Skubis, and D. Vollaro, 1995: External influences on hurricane intensity. Part III: Potential vorticity structure. J. Atmos. Sci., 52, 3593-3606.

,,,--- F. Alsheimer, and H. E. Willoughby, 1998: Potential vorticity analysis of tropical cyclone intensification. J. Atmos. Sci., 55, 2632-2644.

_ D. Dollaro, and K. L. Corbosiero, 2004: Tropical cyclone formation in a sheared environment: A case study. J. Atmos. Sci., 61, 2493-2509.

Montgomery, M. T., and B. F. Farrell, 1993: Tropical cyclone formation. J. Atmos. Sci., 50, 285-310.

_ and its application to spiral bands and intensity changes in hurricanes. Quart. J. Roy. Meteor. Soc., 123, 435-465.

—, M. E. Nicholls, T. A. Cram, and A. B. Saunders, 2006: A vortical hot tower route to tropical cyclogenesis. J. Atmos. Sci., 63, 355-386.

Montroty, R., F. Rabier, S. Westrelin, G. Faure, and N. Viltard, 2008: Impact of wind bogus and cloud- and rain- affected SSM/I data on tropical cyclone analyses and forecasts. Quart. J. Roy. Meteor. Soc., 134, 1673-1699. 
Ndarana, T., and D. W. Waugh, 2011: A climatology of Rossby wave breaking on the Southern Hemisphere tropopause. J. Atmos. Sci., 68, 798-811.

Nguyen, C. M., M. J. Reeder, N. E. Davidson, R. K. Smith, and M. T. Montgomery, 2011: Inner-core vacillation cycles during the intensification of Hurricane Katrina. Quart. J. Roy. Meteor. Soc., 137, 829-844.

Nguyen, L., and J. Molinari, 2012: Rapid intensification of a sheared, fast-moving hurricane over the Gulf Stream. Preprints, 30th Conf. on Hurricanes and Tropical Meteorology, Ponte Vedra Beach, FL, Amer. Meteor. Soc., 7B.5. [Available online at https://ams.confex.com/ams/30Hurricane/webprogram/ Paper204981.html.]

Nolan, D. S., Y. Moon, and D. P. Stern, 2007: Tropical cyclone intensification from asymmetric convection: Energetics and efficiency. J. Atmos. Sci., 64, 3377-3405.

Nong, S., and K. Emanuel, 2003: A numerical study of the genesis of concentric eyewalls in hurricanes. Quart. J. Roy. Meteor. Soc., 129, 3323-3338.

Persing, J., M. T. Montgomery, and R. E. Tuleya, 2002: Environmental interactions in the GFDL hurricane model for Hurricane Opal. Mon. Wea. Rev., 130, 298-317.

Plu, M., P. Arbogast, and A. Joly, 2008: A wavelet representation of synoptic-scale coherent structures. J. Atmos. Sci., 65, 3116-3138.

Qiu, X., Z.-M. Tan, and Q. Xiao, 2010: The roles of vortex Rossby waves in hurricane secondary eyewall formation. Mon. Wea. Rev., 138, 2092-2109.

Ritchie, E. A., and R. L. Elsberry, 2007: Simulations of the extratropical transition of tropical cyclones: Phasing between the upper-level trough and tropical systems. Mon. Wea. Rev., 135, 862-876.

Rossby, C. G., 1940: Planetary flow patterns in the atmosphere. Quart. J. Roy. Meteor. Soc., 66 (Suppl.), 68-87.

Rozoff, C. M., D. S. Nolan, J. P. Kossin, F. Zhang, and J. Fang, 2012: The roles of an expanding wind field and inertial stability in tropical cyclone secondary eyewall formation. J. Atmos. Sci., 69, 2621-2643.
Schubert, W. H., M. T. Montgomery, R. K. Taft, T. A. Guinn, S. R. Fulton, J. P. Kossin, and J. P. Edwards, 1999: Polygonal eyewalls, asymmetric eye contraction, and potential vorticity mixing in hurricanes. J. Atmos. Sci., 56, 1197-1223.

Shapiro, L. J., and H. E. Willoughby, 1982: The response of balanced hurricanes to local sources of heat and momentum. J. Atmos. Sci., 39, 378-394.

Shay, L. K., G. J. Goni, and P. G. Black, 2000: Effects of a warm oceanic feature on Hurricane Opal. Mon. Wea. Rev., 128, $1366-1383$.

Shelton, K. L., and J. Molinari, 2009: Life of a six-hour hurricane. Mon. Wea. Rev., 137, 51-67.

Sitkowski, M., J. Kossin, C. Rozoff, and J. Knaff, 2012: Hurricane eyewall replacement cycle thermodynamics and the relict inner eyewall circulation. Mon. Wea. Rev., 140, 4035-4045.

Thorncroft, C. D., B. J. Hoskins, and M. McIntyre, 1993: Two paradigms of baroclinic-wave life-cycle behaviour. Quart. J. Roy. Meteor. Soc., 119, 17-55.

Vigh, J. L., and W. H. Schubert, 2009: Rapid development of the tropical cyclone warm core. J. Atmos. Sci., 66, 3335-3350.

Wang, Y., 2002: Vortex Rossby waves in a numerically simulated tropical cyclone. Part II: The role in tropical cyclone structure and intensity changes. J. Atmos. Sci., 59, 12391262 .

_ 2012: Does the vertical wind shear profile matter to tropical cyclone intensity change? Preprints, 30th Conf. on Hurricanes and Tropical Meteorology, Ponte Vedra Beach, FL, Amer. Meteor. Soc. [Available online at https://ams.confex.com/ams/ 30Hurricane/webprogram/Paper204806.html.]

Willoughby, H. E., J. A. Clos, and M. G. Shoreibah, 1982: Concentric eyewalls, secondary wind maxima, and the evolution of the hurricane vortex. J. Atmos. Sci., 39, 395-411.

Wirth, V., C. Appenzeller, and M. Juckes, 1997: Signatures of induced vertical air motion accompanying quasi-horizontal roll-up of stratospheric intrusions. Mon. Wea. Rev., 125, 2504-2519. 